\title{
Reliable Evapotranspiration Predictions with a Probabilistic Machine Learning Framework
}

\author{
Hakan Başağaoğlu ${ }^{1, *, \dagger}$, Debaditya Chakraborty ${ }^{2, \dagger}$ and James Winterle ${ }^{1}$ \\ 1 Edwards Aquifer Authority, San Antonio, TX 78215, USA; jwinterle@edwardsaquifer.org (J.W.) \\ 2 Department of Construction Science, University of Texas at San Antonio, San Antonio, TX 78207, USA; \\ debaditya.chakraborty@utsa.edu \\ * Correspondence: hbasagaoglu@edwardsaquifer.org \\ + These authors contributed equally to this work.
}

Citation: Başağaoğlu, H.;

Chakraborty, D.; Winterle, J. Reliable Evapotranspiration Predictions with a Probabilistic Machine Learning Framework. Water 2021, 13, 557. https://doi.org/10.3390/w13040557 Academic Editor: Renato Morbidelli

Received: 7 January 2021

Accepted: 11 February 2021

Published: 22 February 2021

Publisher's Note: MDPI stays neutral with regard to jurisdictional clai$\mathrm{ms}$ in published maps and institutional affiliations.

Copyright: $\odot 2021$ by the authors. Licensee MDPI, Basel, Switzerland. This article is an open access article distributed under the terms and conditions of the Creative Commons Attribution (CC BY) license (https:// creativecommons.org/licenses/by/ $4.0 /)$.

\begin{abstract}
Evapotranspiration is often expressed in terms of reference crop evapotranspiration $\left(E T_{0}\right)$, actual evapotranspiration $\left(E T_{a}\right)$, or surface water evaporation $\left(E_{s w}\right)$, and their reliable predictions are critical for groundwater, irrigation, and aquatic ecosystem management in semi-arid regions. We demonstrated that a newly developed probabilistic machine learning (ML) model, using a hybridized "boosting" framework, can simultaneously predict the daily $E T_{0}, E_{s w}, \& E T_{a}$ from local hydroclimate data with high accuracy. The probabilistic approach exhibited great potential to overcome data uncertainties, in which $100 \%$ of the $E T_{0}, 89.9 \%$ of the $E_{s w}$, and $93 \%$ of the $E T_{a}$ test data at three watersheds were within the models' $95 \%$ prediction intervals. The modeling results revealed that the hybrid boosting framework can be used as a reliable computational tool to predict $E T_{0}$ while bypassing net solar radiation calculations, estimate $E_{s w}$ while overcoming uncertainties associated with pan evaporation \& pan coefficients, and predict $E T_{a}$ while offsetting high capital \& operational costs of EC towers. In addition, using the Shapley analysis built on a coalition game theory, we identified the order of importance and interactions between the hydroclimatic variables to enhance the models' transparency and trustworthiness.
\end{abstract}

Keywords: evapotranspiration; machine learning; probabilistic model; shapley analysis

\section{Introduction}

\section{Background}

Evapotranspiration $(E T)$ is the key component of groundwater budget in droughtprone regions with scarce water supplies [1-3], facing challenges of sustainable development and climate resilience [4]. Reliable prediction of $E T$ is useful to determine aquifer recharge $[5,6]$ in evaluating groundwater sustainability to meet consumptive water use and environmental flow requirements. $E T$ is often reported as reference crop evapotranspiration $\left(E T_{o}\right)$, actual evapotranspiration $\left(E T_{a}\right)$, or potential evapotranspiration from wet surfaces $\left(E T_{p}\right)$, or surfaces covered by large volume of water, such as wetlands or lakes $\left(E_{s w}\right)$.

$E T_{o}$ accounts for climate-driven watershed-scale $E T$ from a surface covered by a hypothetical grass reference crop with uniform height, fully shading the saturated soil, and hence, reflects evaporation power of the atmosphere. The FAO56 Penman-Monteith equation (FAO56 PME) is commonly used to calculate the $E T_{o}$ [7-11]. FAO56 PME-based $E T_{o}$ calculations depend on the climate data, involving time series of shortwave solar radiation $\left(R_{s}\right)$, air temperature $\left(T_{a}\right)$, atmospheric pressure $(P)$, relative humidity $(R H)$, and wind speed $\left(u_{2}\right)$. Because long-term climate data are unavailable in some regions, simplified versions of the FAO56 PME with fewer climate variables have been explored and tested at watersheds with scarce data [12-15]. At the extreme edge, $T_{a}$ was proposed to be the best alternative to $E T_{o}$ [16] or used as a proxy for $E T_{o}$ [17] in hydroclimatic studies. 
However, regional changes in $E T_{o}$ depend also on the trends in other variables such as $R_{S}$, $R H$, and $u_{2}$, which may diminish or exacerbate the role of $T_{a}[18,19]$.

$E T_{0}$ has been commonly used in aridity and drought analysis. For example, $\left(E T_{0}-P_{t}\right)$, in which $P_{t}$ is the precipitation, is used to calculate the standardized precipitation evapotranspiration index (SPEI) in assessment or projection of the meteorological droughts [20,21], although the SPEI was shown to be a poor proxy for projected aridity conditions under global warming [22]. Similarly, $P_{t} / E T_{o}$ represents the drought index and has been used to assess aridity changes under observed and projected global warming conditions [23-25]. $E T_{0}$ has also been used to calculate crop water needs by coupling it with the crop coefficient $\left(k_{c}\right)$ that embodies physiologic characteristics of a specific plant, such as growth stage, crop types, soil characteristics, crop height and leaf area index [26-28].

Evaporation is the key loss term in the closed-basin lake water budget in semi-arid regions [29] that are sensitive to climate change, and evaporation could increase due, in part, to decreases in the ratio of sensible to latent heat flux [30]. Lake evaporation $\left(E_{s w}\right)$ can represent regional $E T_{p}[31]$, which has been used in terrestrial water balance calculations [32] and flood prediction [33]. $E_{s w}$ has been estimated using indirect methods such as Meyer's formula as a function of surface water temperature $\left(T_{s w}\right), R H$, and $u_{2}$ data [34,35], or direct measurements through Eddy covariance (EC) towers [36,37] or pan evaporation methods [38,39]. Evaporation pans are used to determine evaporation from water surface at the pan-scale $\left(E_{p}\right)$, which are then scaled-up to estimate open water evaporation $\left(E_{s w}\right.$ or $\left.E T_{p}\right)$.

However, neither $E T_{o}$ nor $E_{s w}$ provides a direct estimate for $E T_{a}$, which is the sum of evaporation from soil and transpiration from vegetation. As compared to $E T_{o}, E T_{a}$ is more site-specific and spatially-variable, depending on soil and vegetation types. Reportedly, an increase in transpiration from vegetation $\left(E T_{v}\right)$ could result in a two-fold decrease in soil evaporation [40], revealing significant impacts of $E T_{v}$ on $E T_{a}$. EC is the most direct method of measuring land surface water vapor flux [41] without disturbing the water-air interface [42], and hence, provides accurate site-scale $E T_{a}$ measurements [43]. When coupled with the energy balance method, the EC technique provided an alternative measure of latent heat flux equivalent to $E T_{a}[44,45]$.

$E T_{p}$ sets the upper bound for $E T_{a}$ due typically to limited water availability in the soil for evapotranspiration [46,47]. When $E T_{a}<E T_{p}$, moisture becomes limited, the air becomes drier and the excess energy heats up the atmosphere, which subsequently increases $E T_{p}$ [48]. However, $E T_{p} \sim E T_{a} \sim E_{s w}$ holds for wet surface evaporation [49,50]. The ratio $E T_{a} / E T_{o}$ corresponds to the evaporative stress index, and similar to the drought index, it reflects the water and heat properties on the ground surface without requiring complex vegetation and soil hydrological properties in climate classifications [51]. The evaporative stress index was used to study short term droughts [52], irrigation needs for crop growth [53], and water stress [54]. If soil moisture data are available, $E T_{a}$ can be computed by multiplying $E T_{p}$ by the soil moisture extraction function [55].

The background above reveals that different, yet interrelated, ET measures have been used in practice, and their accurate estimates are vital in hydroclimatic applications. Advanced Machine Learning (ML) methods (e.g., Artificial Neural Network (ANN), Support Vector Machine (SVM), Random Forest (RF), Gradient Boost (GBoost), Extreme Gradient Boost (XGBoost)) have also been used to predict $E T_{o}$ [56-59], $E_{p}$ [60-62] and $E T_{a}$ [63]. However, these ML models have been used for a particular ET measure and their prediction accuracy has been evaluated based on the point statistics (e.g., coefficient of determination $\left(R^{2}\right)$ and mean square error $(M S E)$ ), but not 'probabilistically' for more accurate assessment of uncertainties in $E T$ predictions.

\section{Scientific challenge}

Recently, several machine learning (ML) models (e.g. genetic algorithms, neural networks, clustering, tree-based ensembles, fuzzy models, multivariate adaptive regression splines, extreme learning machines, and generalized linear models, deep belief network, support vector machine) have shown promising results due to their ability to upscale or 
simulate the complex nonlinear behavior of $E T_{0}, E_{p}$, and $E T_{a}[14,61,64-75]$. However, a critical challenge with these existing ML models is that the nonlinear relationship between climatic variables and the $E T$ makes it difficult to account for inherent uncertainties [76]. Therefore, in this paper, we confront the uncertainties in $E T$ predictions using a hybrid probabilistic boosting (natural gradient [77] and extreme gradient boosting [78]) ML model without compromising the accuracy of the predictions. The probabilistic model takes in respective feature values $x$ and returns a distribution over the target $y$ indicating the relative likelihood of different values of $y$. To our knowledge, ML-aided probabilistic predictions of $E T_{0}, E_{s w}$, and $E T_{a}$ is unprecedented. Moreover, for the first time we applied a game theory approach [79] to explain the importance of the climate variables on the ML-based $E T_{0}, E_{s w}$, and $E T_{a}$ predictions. This approach manifests how the individual feature values, while considering their interactions with other features, influences the models' predictions, which enhances the models' transparency and trustworthiness.

\section{Research questions, motivations, and objectives}

Considering the presence of different ET prediction methods (e.g., FAO56 PME, Meyer's Formula, Eddy covariance, Machine Learning), a follow-up research question would be: Can we have a unified machine learning model to (i) avoid calibration parameters and empirical relations in predicting $E_{s w}$ (or $E_{p}$ ), (ii) calculate $E T_{o}, E_{s w}$, and $E T_{a}$ simultaneously from the standard hydroclimatic data, (iii) perform probabilistic predictions over the entire solution space for more accurate assessment of uncertainties related to $E T$ estimates, (iv) analyze the order of importance and interactions between the hydroclimatic variables, and (v) explore new hydroclimatic knowledge that may not be readily available from non-probabilistic machine learning, numerical, or empirical models? The main motivations for development of such a model are to (i) have an alternative and complementary method to the FAO56 PME [7] to circumvent net solar radiation calculations in $E T_{o}$ predictions; (ii) overcome uncertainties associated with the pan coefficients, pan evaporation data, and upscaling methods for $E_{s w}$ (or $E T_{p}$ ) estimates; and (iii) reduce the number of required EC towers and/or their operational time length, and hence, to offset high capital \& maintenance costs of EC towers used for $E T_{a}$ measurements. Thus, the main objectives of the paper are to (i) develop a unified 'probabilistic' predictive ML model based on the standard local hydroclimate data to collaterally predict $E T_{0}, E_{s w}$, and $E T_{a}$; and (ii) use Shapley analysis, built on the game theory approach, to determine the order of importance and dependencies \& interactions between hydroclimatic variables in $E T_{0}, E_{s w}$, and $E T_{a}$ predictive models, and compare the results against findings from the current literature.

\section{Study Area \& Data Availability}

The karstic Edwards aquifer in semi-arid south-central Texas is the primary source of drinking water for the city of San Antonio and is also home to several threatened and endangered aquatic species (e.g., Texas blind salamander, San Marcos salamander) at the major spring outlets [80]. Up to $65 \%$ of rainfall is lost to evapotranspiration [81] in southcentral Texas, which has a few permanent surface water and experiences frequent droughts. In some years, anomalously sinking motions and divergent water vapor fluxes over the Texas area reduce precipitation and increase downward solar radiation, which results in dry and hot soil promoting the occurrence of extreme heat waves [82]. Such an extreme summer heat wave occurred in 2011 with average temperature $3^{\circ} \mathrm{C}$ above the $1981-2010$ mean for June through August [83]. The likelihood of exceeding a given unusually high summer temperature in the Texas region was reported to be about 10 times greater with 2011 anthropogenic emissions compared to preindustrial forcing [84]. Under the current and projected climate conditions in south-central Texas, increased air and groundwater temperatures and decreased aquifer recharge and springs flow could make endangered or threatened aquatic species vulnerable to extinction [80,85]. Therefore, reliable estimates of ET are useful for improved management of Edwards aquifer's groundwater and habitats for groundwater-dependent species, as part of the current and future resource planning. 
The Edwards Aquifer Authority (EAA) initiated a pilot program in 2014 to establish a network of weather stations across the Edwards aquifer region to collect local climate data. Measured local climate data at these stations for $E T_{o}$ calculations include $R_{S}, P, T_{a}, R H$, and $u_{2}$. Local climate data at the 15 min intervals from 1 September 2015 to 1 December 2020 were acquired from weather stations at the Nueces Duernell Ranch (NDR) and Bandera County River Authority and Groundwater District's office (BCRAGD) in Figure 1. Local climate data at the Camp Bullis Savanna (CBS) station was available since 25 January 2016. Local hydroclimatic data (including climate data at the NDR, BCRAGD, and CBS sites) used in the numerical and ML analyses are shown in Appendices A.1-A.4.

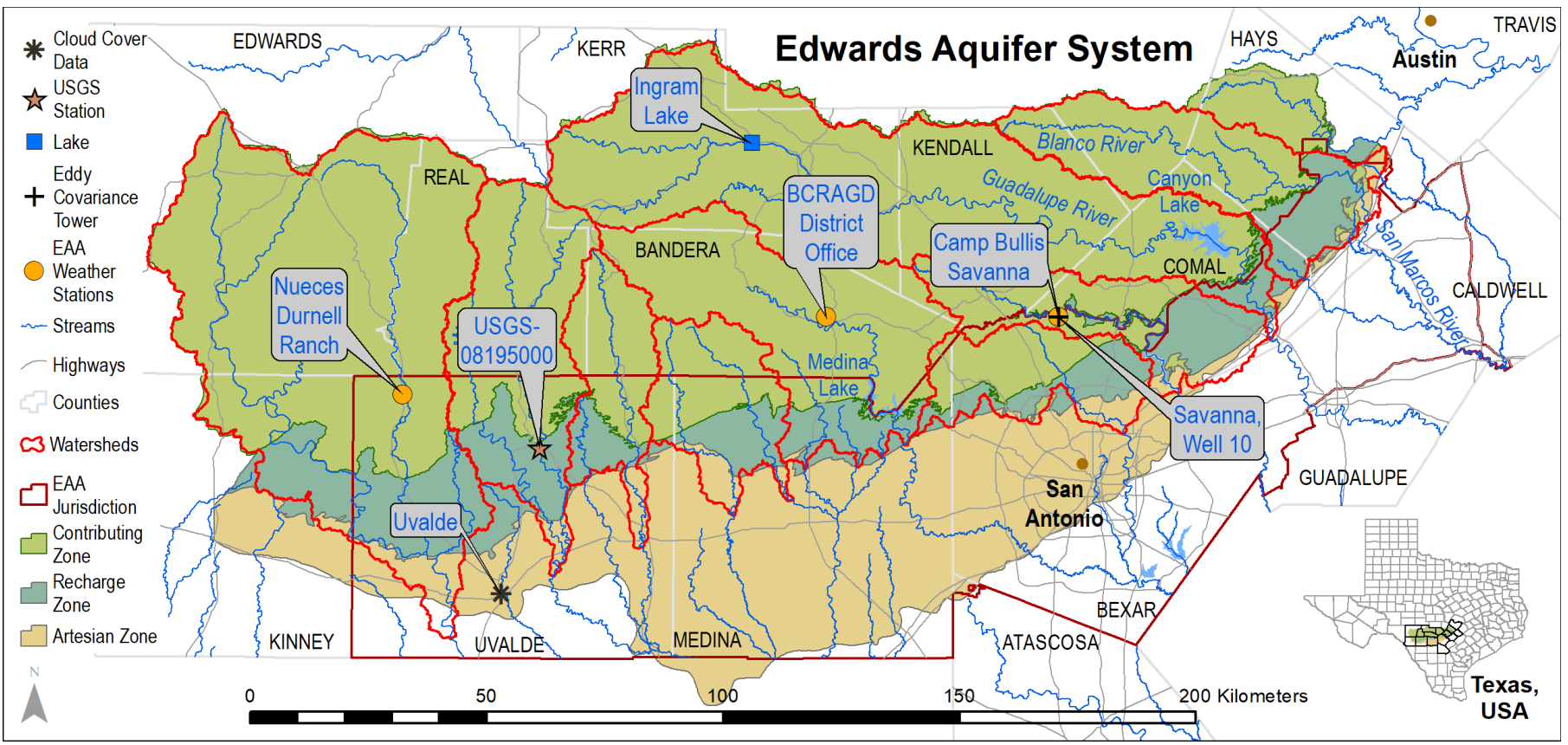

Figure 1. Data source locations across the Edwards aquifer region. The map shows the location of EAA's weather stations with local climate data, the U.S. Geological Survey (USGS)'s station with surface water temperature data, Ingram Lake with estimated lake evaporation data, Uvalde city with the cloud cover data, and the eddy covariance tower with the actual evapotranspiration data.

\section{Methods}

\subsection{FAO56 Penman-Monteith Equation (FAO56 PME)}

Hourly $E T_{0}$ were computed at the NDR, BCRAGD, and CBS stations using the FAO56 PME. The computed $E T_{0}$ were then used to construct the training and testing data for the ML models. Using the FAO56 PME [7], $E T_{o}[\mathrm{~mm} / \mathrm{h}]$ is computed by

$$
E T_{o}=\frac{0.408 \triangle\left(R_{n}-G\right)+\gamma \frac{37}{T_{a}+273} u_{2}\left(e^{o}-e_{a}\right)}{\triangle+\gamma\left(1+0.34 u_{2}\right)},
$$

where $\triangle$ is the slope of the saturation vapor pressure $\left[\mathrm{kPa}{ }^{\circ} \mathrm{C}^{-1}\right], R_{n}$ is the net solar radiation $\left[\mathrm{MJ} /\left(\mathrm{m}^{2} \mathrm{~h}\right)\right], G$ is the heat flux density $\left[\mathrm{MJ} /\left(\mathrm{m}^{2} \mathrm{~h}\right)\right], \gamma$ is the psychrometric constant $\left[\mathrm{kPa}{ }^{\circ} \mathrm{C}^{-1}\right], T_{a}$ is the air temperature $\left[{ }^{\circ} \mathrm{C}\right], e^{o}$ is the saturated vapor pressure $[\mathrm{kPa}]$, $e_{a}$ is the actual vapor pressure $[\mathrm{kPa}]$, and $u_{2}$ is the wind speed measured at $2 \mathrm{~m}$ above the ground surface $[\mathrm{m} / \mathrm{s}] \cdot \gamma=0.665 \times 10^{-3} P . R_{n s}=(1-\alpha) R_{s}$, in which $\alpha$ is the albedo that determines the fraction of the measured solar radiation, $R_{S}\left[\mathrm{MJ} / \mathrm{m}^{2} \mathrm{~h}\right]$, reflected by the surface. $e^{o}=0.6108 e^{T_{a}^{*}}, e_{a}=e^{o}(R H) / 100$, and $\triangle=2503.058 e^{T_{a}^{*}} /\left(T_{a}+237.3\right)^{2}$, in which $R H$ is the relative humidity [-] and $T_{a}^{*}=17.27 T_{a} /\left(T_{a}+237.3\right)$. Hourly-averaged $T_{a}, R H$, $P, u_{2}, e_{a}$, and $e^{o}$, and hourly-aggregated $R_{s}$ are used in Equation (1). Net solar radiation is defined as $R_{n}=R_{n s}-R_{n l}$, in which $R_{n s}$ is the measured net incoming shortwave radiation and $R_{n l}$ is the outgoing longwave radiation $\left[\mathrm{MJ} /\left(\mathrm{m}^{2} \mathrm{~h}\right)\right]$ computed as 


$$
R_{n l}=\left(\sigma T_{a, K}^{4}\right)\left(0.34-0.14 \sqrt{e_{a}}\right)\left(1.35 \frac{R_{s}}{R_{s o}}-0.35\right),
$$

where $\sigma$ is the Stefan-Boltzmann constant $\left(2.043 \times 10^{-10} \mathrm{MJ} /\left(\mathrm{K}^{4} \mathrm{~m}^{2} \mathrm{~h}\right)\right)$ and $T_{a, K}$ is the air temperature in $[\mathrm{K}] . R_{s o}$ is the clear-sky radiation $\left[\mathrm{MJ} /\left(\mathrm{m}^{2} \mathrm{~h}\right)\right]$. Linearized Beer's radiation law leads to $R_{s o}=\left(0.75+2 \times 10^{-5} z\right) R_{a}$, in which $z$ is the elevation of the weather station above the sea level [m] and $R_{a}$ is the extraterrestrial radiation $\left[\mathrm{MJ} /\left(\mathrm{m}^{2} \mathrm{~h}\right)\right]$. In other words, $R_{s o} \sim 0.75 R_{a}$, which accounts for $25 \%$ reduction in $R a$ due to the interaction of $R_{a}$ with atmospheric gases [86,87]. $\left(R_{s} / R_{s o}\right)$ is the relative shortwave radiation, representing the cloud cover, defined as

$$
0.33 \leq \frac{R_{s}}{R_{s o}} \sim \frac{R_{s}}{\left(0.75+2 \times 10^{-5} z\right) R_{a}} \leq 1.0,
$$

in which the lower bound of 0.33 and the upper bound of 1.0 represent the dense cloud cover and clear sky on a particular day, respectively. The first, second, and third terms in Equation (2) account for the effect of air temperature, air humidity, and cloudiness on $R_{n l}$. $R_{a}$ depends on the geographic location of the weather station and time of the day, and is computed as

$$
R_{a}=\frac{720 G_{s c} d_{r}}{\pi}\left[\left(\omega_{2}-\omega_{1}\right) \sin (\varphi) \sin (\delta)+\cos (\varphi) \cos (\delta)\left(\sin \left(\omega_{2}\right)-\sin \left(\omega_{1}\right)\right)\right],
$$

where $G_{s c}$ is the solar constant $\left[0.0820 \mathrm{MJ} /\left(\mathrm{m}^{2} \mathrm{~min}\right)\right], d_{r}$ is inverse relative distance earthsun [-], $\delta$ is the solar declination [rad], $\varphi$ is the latitude of the weather station [rad], $\omega_{1}$ and $\omega_{2}$ are the solar time angle at the beginning and end of the period [rad]. Here, $d_{r}=1+0.033 \cos (2 \pi J / 365)$ and $\delta=0.409 \sin (2 \pi J / 365-1.39)$, in which $J$ is the day count of the year. Solar time angle at midpoint of hourly period, $\omega[\mathrm{rad}]$, is given by

$$
\omega=(\pi / 12)\left[\left(t+0.06667\left(L_{z}-L_{m}\right)+S_{c}\right)-12\right],
$$

in which $t$ is the standard clock time at an half-and-hour intervals [h], $L_{z}=90^{\circ}$ for central Texas, $L_{m}$ is the longitude of the weather station [degrees], and $S_{c}$ is the seasonal correction for solar time [h], given by $S_{c}=0.1645 \sin (2 b)-0.1255 \cos (b)-0.025 \sin (b)$, in which $b=2 \pi(J-81) / 364 . \omega_{1}=\omega-\left(\pi t_{1} / 24\right)$ and $\omega_{2}=\omega+\left(\pi t_{1} / 24\right)$. Here, $R_{a}=0$ when the sun is below the horizon at $\omega<-\omega_{s}$ or $\omega>\omega_{s}$. To keep the cloudiness, $R_{s} / R_{s o}$ in Equation (3), and hence, $R_{n l}$ in Equation (2) finite, $R_{s} / R_{s o}$ at night times is set to $R_{s} / R_{s o}$ value $2-3 \mathrm{~h}$ prior to sunset. The sunset time in each day of the year can be identified by $\left(\omega_{s}-0.79\right) \leq \omega \leq\left(\omega_{s}-0.52\right)$. When the sun is above the horizon $\left(R_{a}>0\right), G=0.1 R_{n}$ corresponds to smaller heat outfluxes, promoting soil warming during day times. In contrast, when the sun is below the horizon $\left(R_{a}=0\right), G=0.5 R_{n}$ corresponds to larger heat outfluxes, promoting soil cooling at nights. Wind speed, $u_{2} \geq 0.5 \mathrm{~m} / \mathrm{s}$ in $E T_{o}$ calculations to account for the effects of boundary layer instability and buoyancy of air in promoting exchange of vapour at the surface when air calm.

\subsection{Meyer's Formula (MF)}

The MF model was used here to verify the reasonability of $E_{s w}$ data produced by upscaling the $E_{p}$ data, as the $E_{s w}$ data were subsequently used to train and test the ML models. MF is a mass transfer-based, empirically constructed formula [88] used to calculate daily or monthly $E_{s w}$. It is expressed in the form of $E_{s w}=\beta\left(e^{o}-e_{a}\right)$, in which $\beta$ is the empirically determined constant, $e^{o}$ and $e_{a}$ are defined in terms of surface water temperature $\left(T_{s w}\right)$, unlike in the FAO56 PME. Reportedly, the best form of the MF to predict daily $E_{s w}$ from free water surface [34]

$$
E_{s w}=0.35\left(1+0.98 / 100 u_{2}\right)\left(e^{o}-e_{a}\right),
$$


where $u_{2}$ is expressed in [mm/d], and $e^{o}$ and $e_{a}$ are expressed in [mm-Hg] in Equation (6).

\subsection{Probabilistic Machine Learning Models}

We used NGBoost's (natural gradient boosting [77]) modular design to hybridize it with XGBoost (extreme gradient boosting) base learners to enhance the resulting model's predictive capability-i.e., producing probabilistic predictions of the continuous variables in addition to delivering accurate point predictions. Technical explanation for the NGBoost and XGBoost models are provided in Appendix B.

As shown in Figure 2, the input feature vector $x$ in the hybrid NGBoost-XGBoost model is passed on to the XGBoost base learners to produce a probability distribution of the predictions $P_{\theta}(y \mid x)$ over the entire outcome space $y$ (that is, $E T_{0}, E T_{a}$, and $E_{s w}$ ). The models are then optimized by scoring rule $S\left(P_{\theta}, y\right)$ using a maximum likelihood estimation function that yields calibrated uncertainty and point predictions. The feature vector $x$ for $E T_{o}$ predictions consists of $T_{a}, P, R H, u_{2}, R_{s}$, and month; the feature vector $x$ for $E T_{a}$ predictions includes $E T_{0}, T_{a}, P, R H, u_{2}, R_{s}$, and month; and the feature vector $x$ for $E_{s w}$ predictions consists of $T_{s w}, T_{a}, P, R H, u_{2}, R_{s}$, and month. Since XGBoost is designed to produce only point predictions [78] and NGBoost is not specifically designed for point predictions [77], the hybridization provides the best of both models.

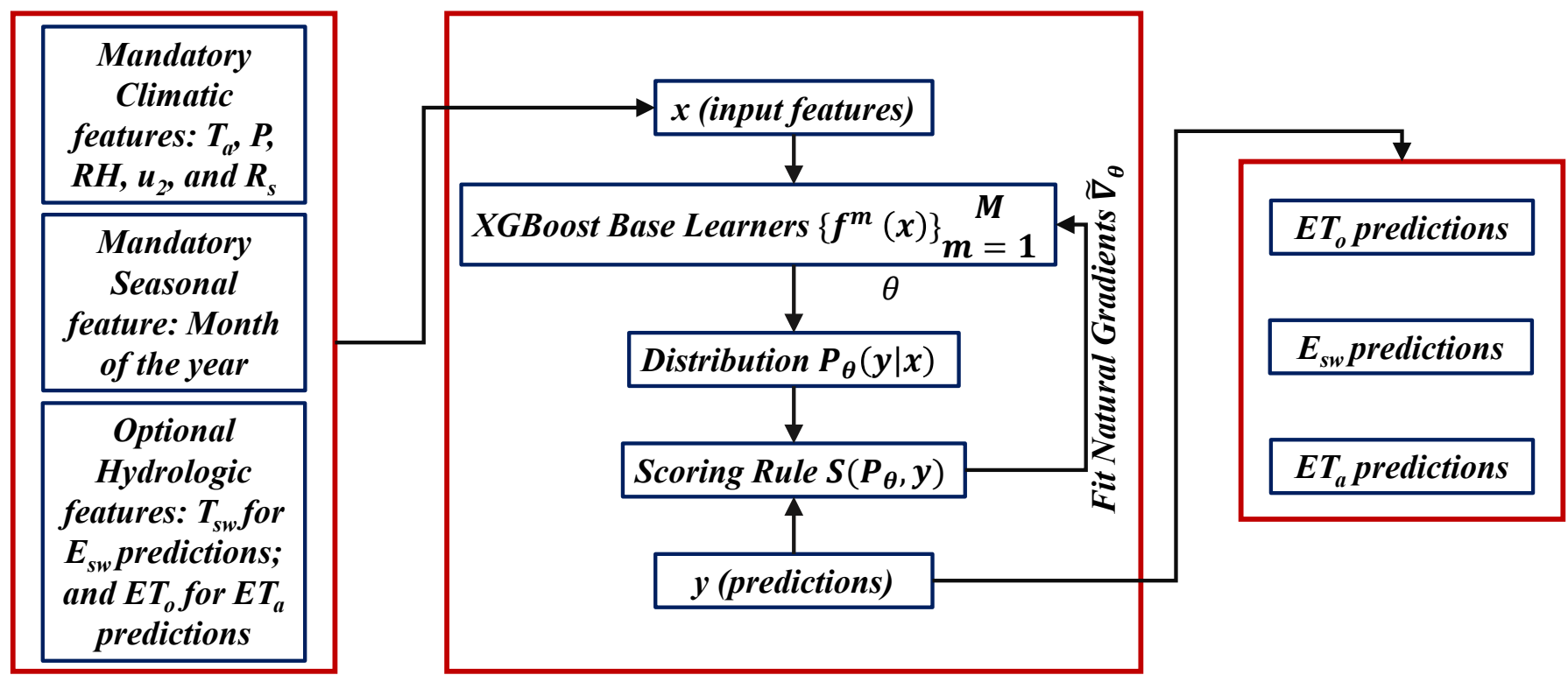

Figure 2. Conceptual representation of the hybrid NGBoost-XGBoost model for $E T_{0}, E_{s w}$, and $E T_{a}$ prediction.

\section{Results}

\subsection{ET Predictions Using FAO56 PME and MF}

Hourly $E T_{o}$ were calculated with Equation (1), using local climate data at the NDR, BCRAGD, and CBS stations. Daily and monthly $E T_{o}$ at the NDR site are shown as an example in Figure 3a. $E T_{o}$ values at nighttime hours occasionally take on negative values. In some situations, negative hourly $E T_{o}$ may indicate condensation of vapor during periods of early morning dew [26]. Hourly $E T_{o}<-1 \times 10^{-3} \mathrm{~mm}$ occurred $<0.1 \%$ of the times in our study area. Under these conditions, net condensation of water from the atmosphere is possible. However, on a daily basis $E T_{o}$ values were persistently non-negative, as expected for a semi-arid region. Predicted daily and monthly $E_{s w}$ (from pan evaporation data) at Ingram Lake are in good agreement with the estimated $E_{s w}$ at Ingram Lake using Equation (6) and local climate data from the NDR station or the BCRAGD station (Figure $3 b$ ). Figure $3 c$ shows that $E T_{o}$, in general, set the lower bound for $E_{s w}$ at Ingram Lake for the entire period. In 2016, $E T_{o} \sim E_{s w}$ for most of the year except in December. Although $E_{s w}>E T_{o}$ in the summer of the following years, with the largest difference in 
the summer of 2018, $E T_{o}$ appears to be a reliable predictor for $E_{s w}$ especially in spring and winter months. Figure $3 \mathrm{~d}$ compares daily or monthly Bowen-ratio-corrected $E T_{a}$ measurements from the EC tower against $E T_{0}$ computed by the FAO56 PME, using local climate data from the CBS station. According to this plot, $E T_{o} \geq E T_{a}$ during the monitoring period, as expected. In some summer months, $E T_{o}$ was about three times higher than $E T_{a}$ (e.g., July 2017), indicating that the soil was too dry in summer times to contribute to the evapotranspiration at the CBS site.

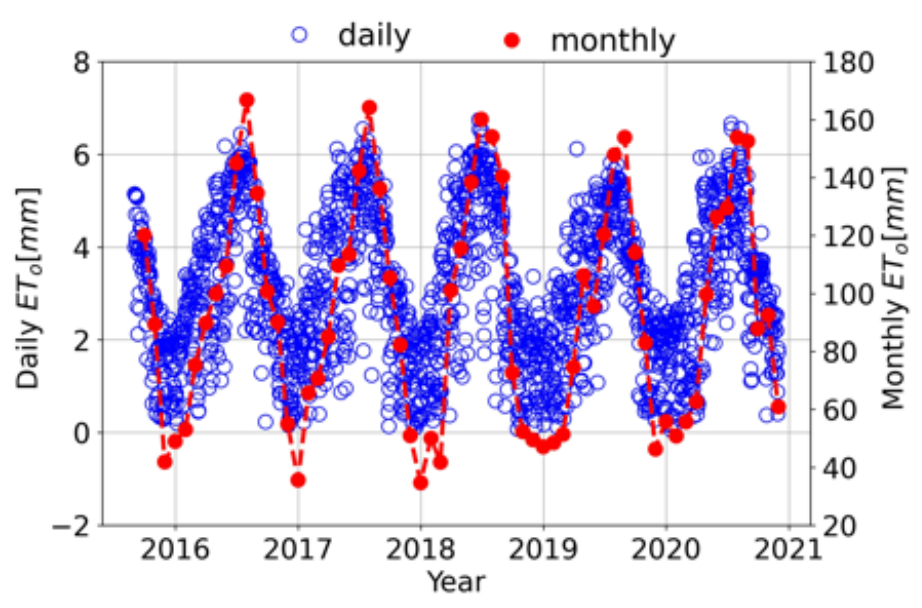

(a) Reference crop evapotranspiration (FAO56 PME-ETo)

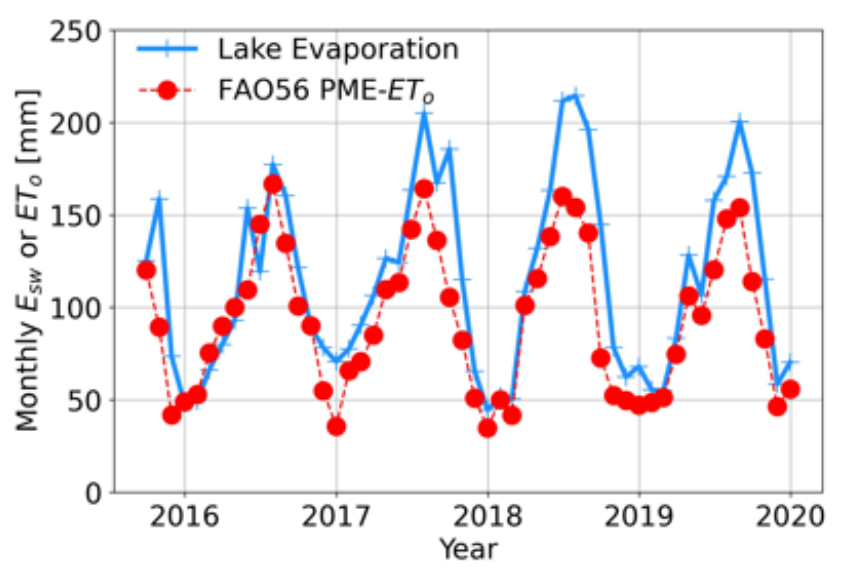

(c) Lake evaporation vs. FAO56 PME-ET。

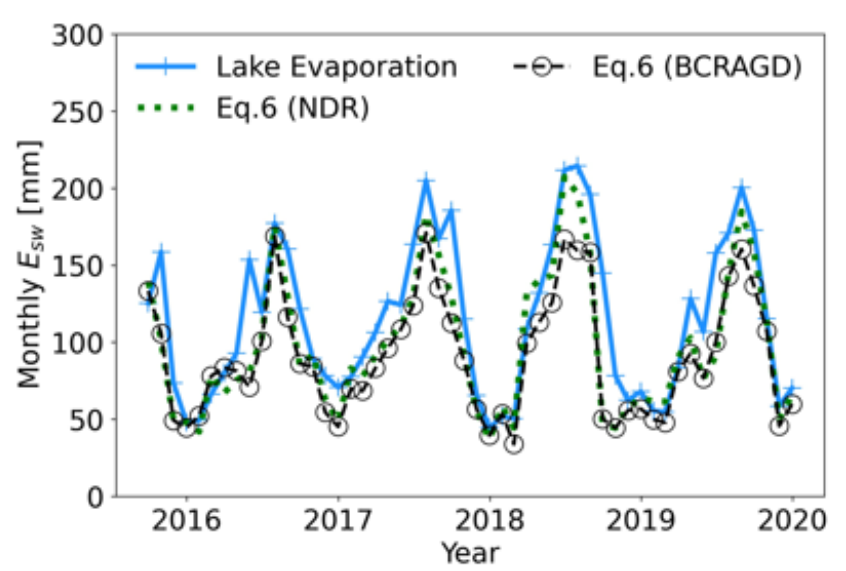

(b) Lake evaporation using MF

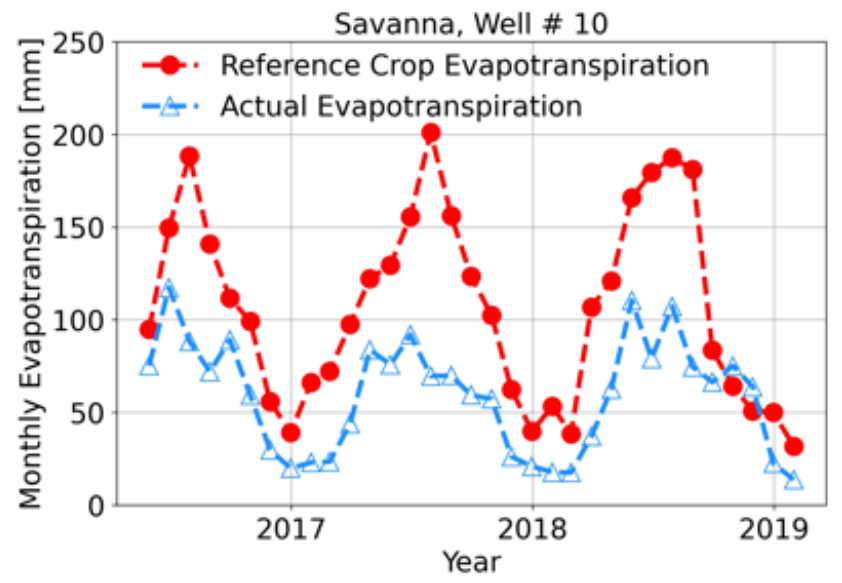

(d) Actual evaporation vs. FAO56 PME-ET。

Figure 3. Computed $E T_{o}$ and $E_{s w}$ and measured $E_{s w}$ and $E T_{a}$ data.

The results in Figure 3 indicate that $E T_{a} \leq E T_{o} \leq E_{s w}$, which verifies the reliability of the local hydroclimatic data used in $E T_{0}, E_{s w}$, and $E T_{a}$ predictions for the semi-arid region. In the subsequent analysis, hourly $E T_{o}$ were aggregated to daily values, as the $E_{s w}$ and $E T_{a}$ data were available to us in daily time-stamps. Daily $E T_{0}, E_{s w}$, and $E_{a}$ were then used to train and test the ML models. Because the data available at the CBS site was nearly half the data available at the NDR site for training the corresponding ML model, $90 \%$ of the existing data were used for training to unravel the relationship between the climatic features and the $E T_{a}$. Therefore, we consistently applied the 90-10 (train-test) percentage split of datasets at all sites to train the corresponding ML models.

\subsection{ET Predictions Using Probabilistic ML Models}

We investigated if daily $E T_{o}$ can be accurately computed by the probabilistic ML model using local climate data, as an alternative to Equation (1). The ML model was trained by using $90 \%$ of the daily climate data \& the month of the year as features, and 
the FAO56 PME-computed $E T_{o}$ data as the target. Subsequently, the trained ML model was used to predict $E T_{0}$ for the remaining $10 \%$ of the data. In the end, ML-predicted daily $E T_{o}$ were compared against FAO56 PME-computed daily $E T_{o}$ to assess the performance of the ML-model on the testing data. Differences between the ML-predicted $E T_{0}$ from the FAO56 PME-computed $E T_{o}$ on the testing dataset are shown in Figure $4 \mathrm{a}$, in which $100 \%$ of the FAO56 PME-computed $E T_{o}$ were within the model's $95 \%$ prediction interval. In other words, the model $100 \%$ of the time successfully predicted $E T_{o}$ value within the $95 \%$ confidence interval. In addition, based on point statistical measures in Table 1, probabilistic prediction of $E T_{o}$ by the hybrid NGBoost-XGBoost model can be used as a reliable alternative method to estimate watershed-scale $E T_{0}$. The total training time for the $E T_{0}$ hybrid model was $\sim 39$ min that involved choosing the optimum model out of 230 candidates using a 3-fold grid search cross-validation technique, which equates to 690 model fits on an Intel Core i9-9980XE processor and 64 GB RAM computer. The main advantage of the ML-based $E T_{o}$ prediction model is that it avoids extra-terrestrial, clear-sky, and longwave solar radiation calculations, as part of the net solar radiation calculations.

Table 1. Hybrid NGBoost-XGBoost ML model accuracy test with statistical measures and comparison to a baseline random forest model.

\begin{tabular}{|c|c|c|c|c|c|c|}
\hline & Model & Data & $\begin{array}{c}\text { RMSE * } \\
(\mathrm{mm})\end{array}$ & $\operatorname{MAE}^{\dagger}(\mathrm{mm})$ & $R^{2} \ddagger$ & $C_{f}^{\S}(\%)$ \\
\hline \multirow[t]{4}{*}{$E T_{o}$} & Random Forest & Training data only & 0.064 & 1.345 & 0.998 & - \\
\hline & & Testing data only & 0.163 & 1.360 & 0.990 & - \\
\hline & NGBoost-XGBoost & Training data only & 0.098 & 0.074 & 0.996 & 100 \\
\hline & & Testing data only & 0.124 & 0.092 & 0.994 & 100 \\
\hline \multirow[t]{4}{*}{$E_{s w}$} & Random Forest & Training data only & 0.324 & 1.493 & 0.967 & - \\
\hline & & Testing data only & 0.870 & 1.504 & 0.776 & - \\
\hline & NGBoost-XGBoost & Training data only & 0.703 & 0.545 & 0.843 & 99.1 \\
\hline & & Testing data only & 0.918 & 0.736 & 0.750 & 89.9 \\
\hline \multirow[t]{4}{*}{$E T_{a}$} & Random Forest & Training data only & 0.192 & 1.003 & 0.973 & - \\
\hline & & Testing data only & 0.580 & 1.005 & 0.767 & - \\
\hline & NGBoost-XGBoost & Training data only & 0.414 & 0.311 & 0.876 & 99.4 \\
\hline & & Testing data only & 0.537 & 0.418 & 0.801 & 93 \\
\hline
\end{tabular}

$\left.{ }^{*}\right)$ Root mean square error; + Mean absolute error; $\ddagger$ Coefficient of determination; $§$ Percentage of datapoint within the model’s 95\% prediction interval.

The ML-based $E_{s w}$ prediction model was trained by using the first $90 \%$ of the daily climate data \& the month of the year as features, and the measured $E_{s w}$ data as the target. Subsequently, the model was tested on the remaining $10 \%$ of the data. The comparison between ML-predicted daily $E_{s w}$ and the measured $E_{s w}$ on the testing data is shown in Figure $4 \mathrm{~b}$. The ML-predicted $E_{s w}$ matched the measured $E_{s w}$ very closely, and $89.9 \%$ of the actual $E_{s w}$ were within the model's $95 \%$ prediction interval in the testing dataset. Based on the statistical measures in Table 1, the hybrid NGBoost-XGBoost model can be used as a reliable method for $E_{s w}$ predictions. The total training time for the $E_{s w}$ hybrid model was $\sim 6 \mathrm{~min}$, including the elapsed time for choosing the optimum model from 690 model fits. The main advantage of the ML-based $E_{s w}$ prediction model is that $E_{s w}$ predictions are not affected by anomalies in $E_{p}$ measurements (Figure A4a) or uncertainties in monthly pan evaporation coefficients. 


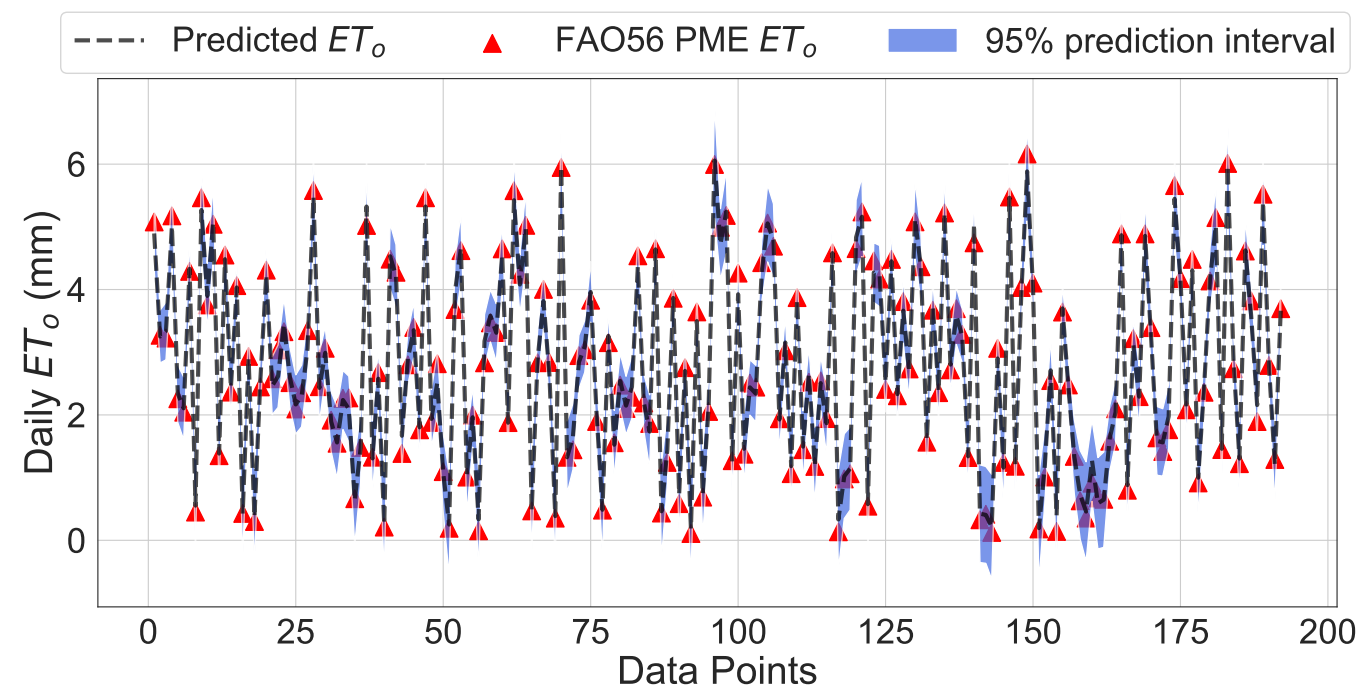

(a) $E T_{o}$ predictions on the testing data

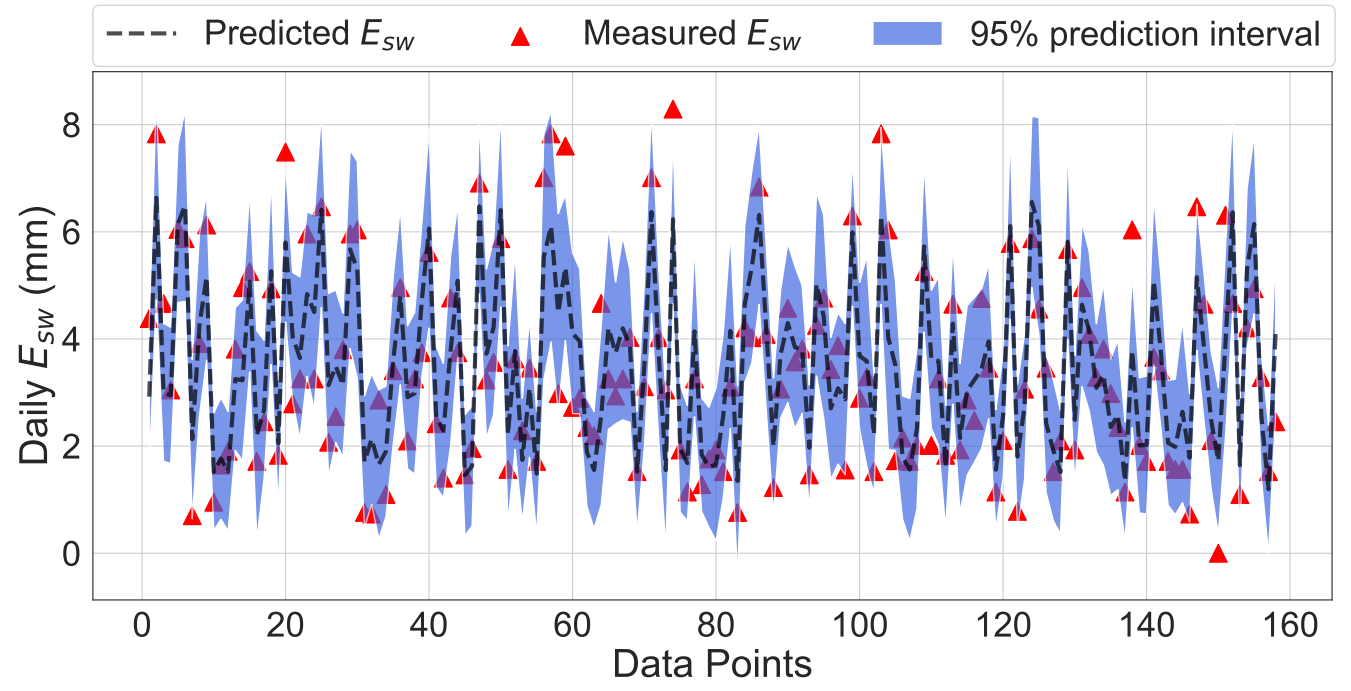

(b) $E_{s w}$ predictions on the testing data

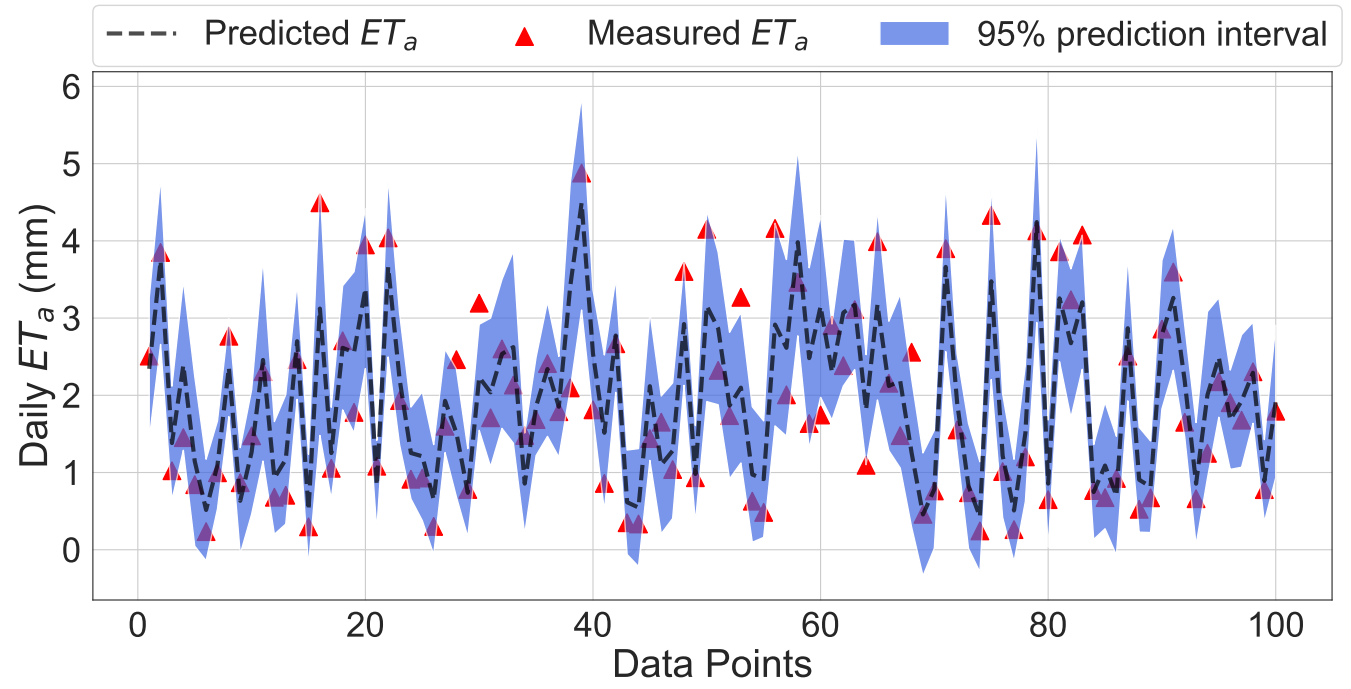

(c) $E T_{a}$ predictions on the testing data

Figure 4. Graphical representation of the predictive capability of the hybrid NGBoost-XGBoost model. 
The ML-based $E T_{a}$ prediction model was trained by using the first $90 \%$ of the daily climate data, FAO56 PME-computed $E T_{0}$, \& the month of the year as features, and the measured $E T_{a}$ data as the target. Subsequently, the model was tested on the remaining $10 \%$ of the data. The comparison between ML-predicted daily $E T_{a}$ and the actual $E T_{a}$ measurements on the testing data is shown in Figure 4c, in which $93 \%$ of the actual $E T_{a}$ values were found within the model's $95 \%$ prediction interval. ML-based $E T_{0}$ predictions were more accurate than the $E T_{a}$ predictions due, in part, to the availability of less data from the EC tower at the CBS site than at Ingram Lake or the NDR site for the ML-model training. However, based on the statistical measures in Table 1, probabilistic prediction of $E T_{a}$ by the hybrid NGBoost-XGBoost ML model (with $R^{2}=0.801$ on testing data) can be used as a reliable method to estimate $E T_{a}$. The total training time for the $E T_{a}$ hybrid model was $\sim 9 \mathrm{~min}$, including the 690 model fits to choose the optimum model. The main advantage of the ML-based $E T_{a}$ prediction model is that it can be used to reduce the number of required EC towers and/or their operational time length, and hence, offset the high capital and maintenance costs for the installation and operation of EC towers to acquire $E T_{a}$ measurements.

In Ref. [59], we had compared the predictive performance of the non-probabilistic ML models-including XGBoost, support vector machines (SVM), long short-term memory networks (LSTM), deep learning (DL), random forest (RF), and linear regression (LR)-in predicting $E T_{0}$ from structured tabular datasets acquired from multiple weather stations. In that study, the top performing interpretable XGBoost model exhibited comparable predictive accuracy to the top performing noninterpretable DL model. RF was identified as the second best interpretable model, which resulted in comparable but, slightly lower predictive accuracy than XGBoost, and outperformed the predictive accuracy of SVM, LSTM, and LR. Based on the analysis in Ref. [59], we chose RF as the baseline model in this study to establish a point of reference for analyzing the performance of the hybrid NGBoost-XGBoost ML model. Table 1 shows that the hybrid model exhibited better predictive performance than RF in terms of point predictions of both $E T_{o}$ and $E T_{a}$ on the testing data. Conversely, RF produced better point predictions of $E_{s w}$ than the hybrid model but, more importantly, unlike the RF model, the hybrid model was capable of providing prediction intervals and uncertainty estimates for $E T_{0}, E_{s w}$, and $E T_{a}$, and hence, overcoming the scientific challenge discussed in Section 1.

\subsection{Feature Importance in $E T_{0}, E_{s w}$, and $E T_{a}$ Predictive $M L$ Models Using a Game Theory Approach}

It is imperative for end-users to peek inside ML models to better understand how the features contribute to the model predictions or how they affect the overall model performance. The climatic variables $\left(T_{a}, P, R H, u_{2}, R_{s}\right)$ in Equation (1) were chosen as the features for the $E T_{o}$ predictive model. The same climatic variables were used as the features for the $E T_{a}$ predictive model, in addition to $E T_{o}$ to quantify its contribution to $E T_{a} . T_{s w}$ in Equation (6) was added as a new feature to the climatic variables in the $E_{s w}$ predictive model. Moreover, 'month' was included as an additional feature in all predictive models based on the observed seasonality in $T_{s w}$ data, $E T_{a}$ measurements from the EC tower, and expected seasonality in soil moisture content at the site where the the EC tower is located.

We investigated the relationship and contribution of each feature to the prediction of the $E T_{0}, E_{s w}$, and $E T_{a}$ models (Figure 5a) using Shapley values [79] based on coalition game theory. The Shapley value is the average marginal contribution of each feature value across all possible combinations of features. The features with large absolute Shapley values are deemed important. To obtain the global feature importance, we average the absolute Shapley values for every feature across the data, sort them in decreasing importance and plot them. Each point on the plot represents a Shapley value for individual features and instances. The position on the $\mathrm{x}$ - \& the $\mathrm{y}$-axis is determined by the Shapley values \& the feature importance, respectively, and the color scale depicts the feature importance from low to high. 


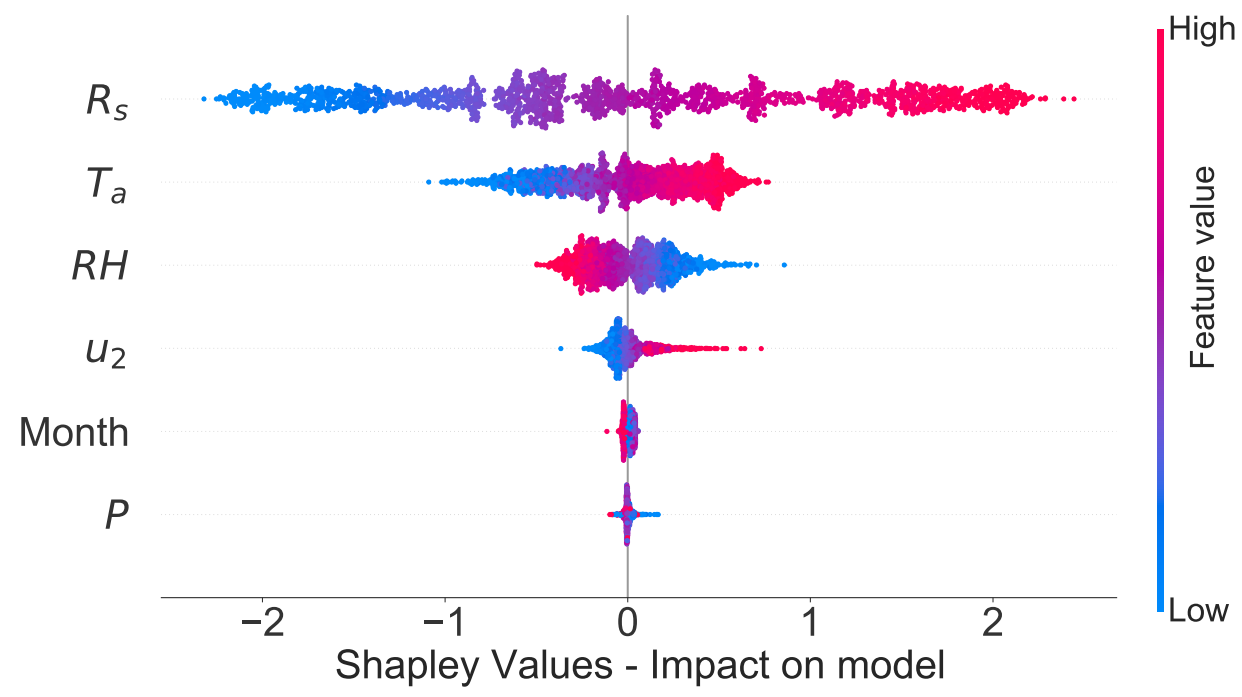

(a) Feature importance-E $E T_{0}$ predictive model

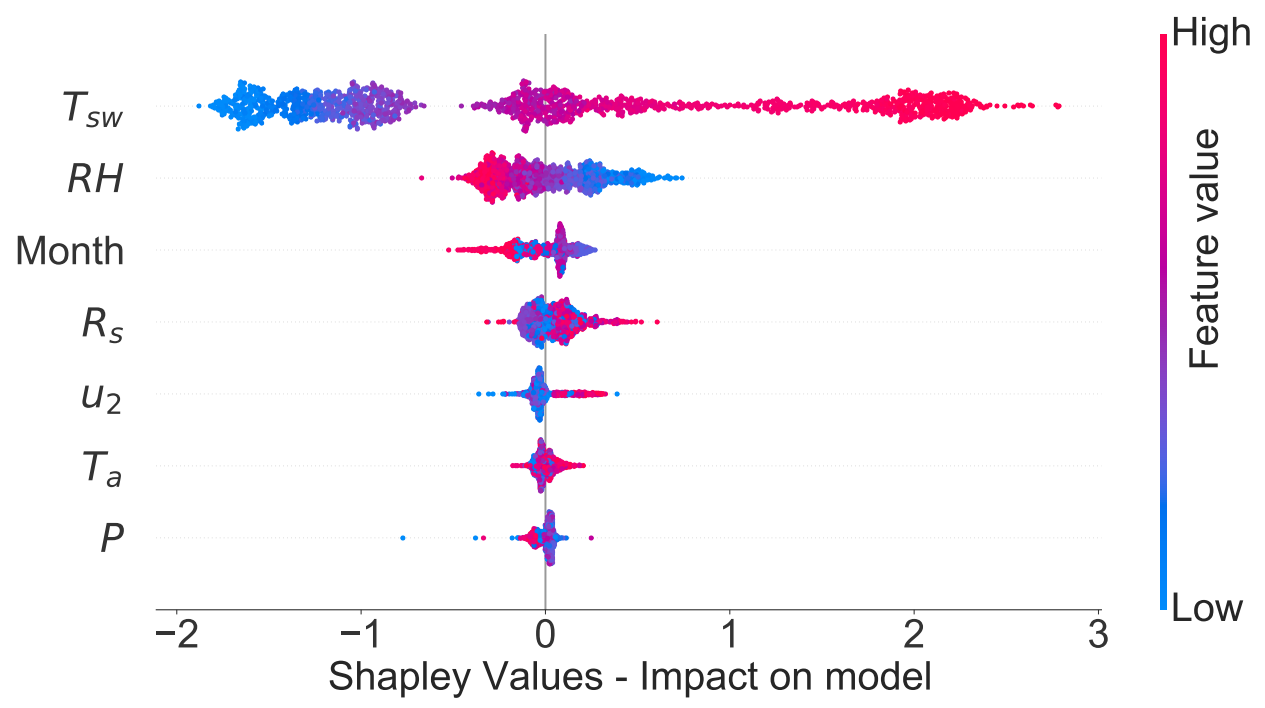

(b) Feature importance- $E_{s w}$ predictive model

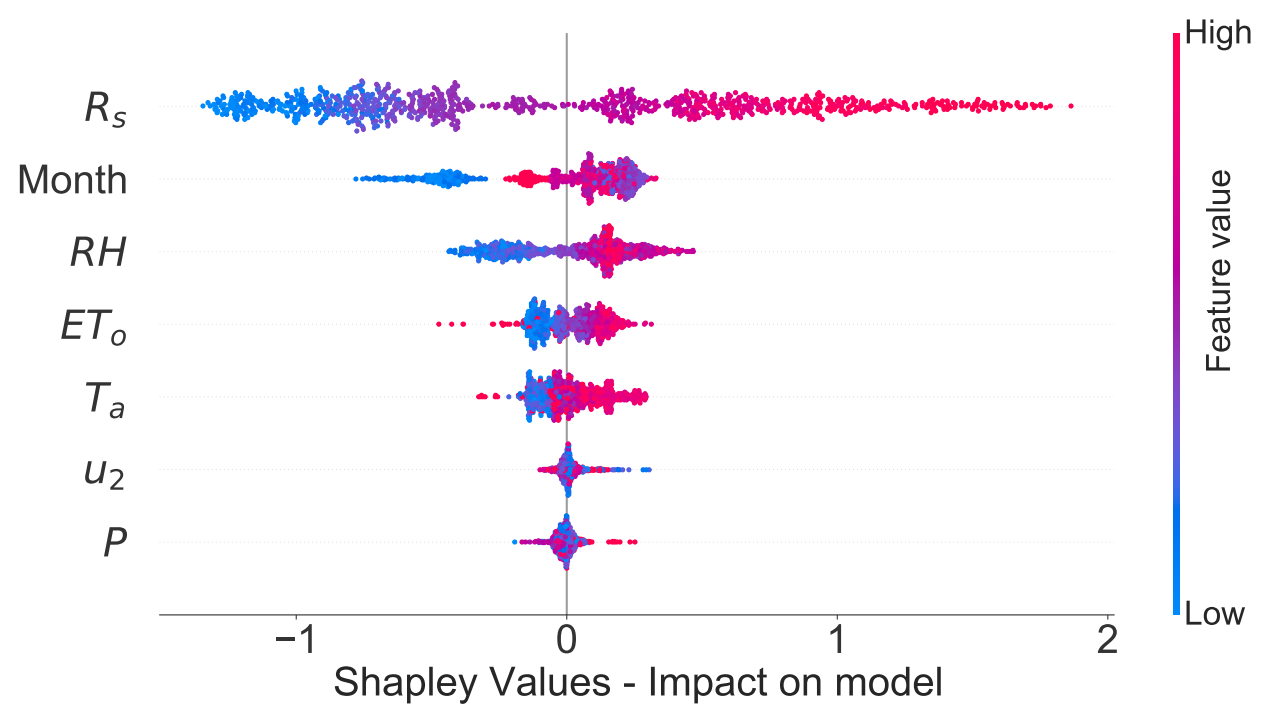

(c) Feature importance- $E T_{a}$ predictive model

Figure 5. The order of importance of hydroclimate variables on the $E T_{o}, E_{s w}$, and $E T_{a}$ predictions. 
Figure 5a shows that the order of importance of local climate variables from the highest to the lowest on the predicted $E T_{o}$ involves the $R_{s}, T_{a}, R H, u_{2}, \& P$. The month of the year is deemed to be the second least important feature for the $E T_{o}$ model. Figure $5 \mathrm{~b}$ shows that, unlike $E T_{0}, E_{s w}$ is largely impacted by the $T_{s w}$ followed by $R H . T_{a}$ is given lower importance because of the high correlation $\left(R^{2}=0.95\right)$ between $T_{s w}$ and $T_{a}$ (Figure A6b), and thus, the model considers $T_{a}$ as redundant. Moreover, Figure $5 \mathrm{~b}$ unveils the model's understanding of the underlying hydrological process. For example, after being trained with the historical data, the model predicts higher $E_{s w}$ (represented by higher Shapley value on the x-axis) when $T_{s w}$ are high (represented as red dots) and $R H$ are low (represented as blue dots), capturing the underlying physics correctly, and hence, evidencing the model capability of making learning-based conscious predictions.

For the $E T_{a}$ predictions, $R_{s}$ was followed by the month of the year, and $R H$, and $T_{a}$ are the next most important climatic features for $E T_{a}$ predictions, as shown in Figure $5 c$. However, in comparison to $E T_{0}, E T_{a}$ depends less strongly on $R_{s}\left(R^{2}=0.77\right.$, as shown in Figure A6c), as the time-dependent soil moisture and vegetation transpiration also impact $E T_{a}$ measurements, unlike for FAO56 PME-computed $E T_{o}$ in Equation (1). Besides, the analysis did not reveal a strong impact of $E T_{o}$ on the $E T_{a}$ predictions, because FAO56 PME$E T_{o}$ calculations are based on the assumption of a hypothetical reference crop growing in a saturated soil (Section 3.1), and hence, not accounting for the effect of temporally-varying transpiration rates from the actual vegetation (open oak savanna at the EC tower site) and the transient nature of the soil moisture content affecting $E T_{a}$ measurements. Due to the temporal variations in water uptake, vegetation transpiration, and soil moisture content on the field near the EC tower, where $E T_{a}$ measurements were taken, the month of the year became a strikingly more important feature in the $E T_{a}$ model than in the $E T_{o}$ model.

After all, the Shapley values represented the underlying physics accurately in ranking the hydroclimate variables in the order of their importance in predicting different $E T$ measures. In the next section, we compare our Shapley results against the order of importance of hydroclimate variables for ET predictions in the literature that have been typically obtained from sensitivity or correlation analyses, which are not capable of accounting for the interdependency among all the features.

\section{Discussion}

\subsection{What the Hybrid NGBoost-XGBoost Model Accomplished?}

$E T_{a}$ is the most critical $E T$ estimate, especially for irrigation, agricultural, and water resources management practices. The EC method provides accurate prediction for $E T_{a}$; however, the associated capital and maintenance costs are high. For example, the capital cost for the EC tower at the CBS site was about $\$ 40,000$ and required frequent maintenance. $E_{s w}$ measurements are important indicators of global climate change [30], which could affect the water levels \& chemistry. Pan evaporation method is a simple, inexpensive, and widely-used data acquisition method to predict $E_{s w}$ at open water bodies, but suffers from uncertainties in pan evaporation measurements and in pan coefficients when water evaporation is upscaled from the pan-scale to the large open-water body-scale. $E T_{0}$ is often computed by FAO56 PME that relies on local climate variables and net solar radiation calculations.

We demonstrated in Section 4.2 that using the standard local climate data as the independent feature, the hybrid NGboost-XGBoost model can simultaneously predict (i) $E T_{0}$-without requiring net solar radiation calculations - as an alternative or complementary method to FAO56 PME calculations; (ii) $E_{s w}$ while eliminating uncertainties associated with pan evaporation measurements and pan evaporation coefficients needed to upscale $E_{p}$ to $E_{s w}$; and (iii) $E T_{a}$ while offsetting the high capital and operational costs for EC towers by potentially reducing their numbers and operational length. In addition, the NGBoostXGBoost model exhibited great potential in overcoming data uncertainties, in which more than $89.9 \%$ of $E T o, E_{s w}$, and $E T_{a}$ test data were within the model's $95 \%$ prediction interval, which is essential to use such models with confidence in practice. Moreover, unlike the 
black-box models (e.g., deep learning models) [89], the hybrid NGboost-XGBoost model provided explanation for the nonlinear and complex ET processes, as elaborated next.

\subsection{How Shapley Analysis Results Compare to Findings in the Current Literature?}

We explained the nonlinear feature dependencies on the $E T_{0}, E_{s w}$, \& $E T_{a}$ predictions using Shapley analysis, based on a game theory, to enhance the interpretability of the ML model and explainability of the ML model results. The Shapley analysis is advantageous over traditional sensitivity and correlation analysis as it explicitly considers the interaction and interdependency among the predictive variables in predicting the target variables.

The findings in Figure 5 are useful to evaluate the suitability of the simplified versions of the FAO56 PME proposed for semi-arid watersheds with scarce climate data. Irmak et al. [12] proposed two simplified FAO56 PMEs that require less number of climate variables to calculate the net radiation $\left(R_{n}\right.$ in Equation (1)). The first equation relied on the measured $T_{a}$ and $R_{s}$, whereas the second equation relied on predicted $R_{s}$, and measured $T_{a}$ and $R H$. Although the simplified equations were used to estimate $R_{n}$ only, the second equation built on the three most important climate variables, identified in Figure $5 \mathrm{a}$, for more accurate $E T_{0}$ estimates is expected to perform better for the semi-arid regions, if the predicted $R_{S}$ has low uncertainty. This is consistent with the conclusion by Irmak et al. [12] that the second equation accounted for $79 \%$ of the variability in $R_{n}$ in their case studies.

Chia et al. [73] noted that $T_{a}$ and $R_{s}$ are the most critical climate variables to estimate $E T$ in semi-arid regions. Our results in Figure 5a agree with their statement; however, $R H$ also needs to be included for enhanced prediction accuracy of $E T_{0}$. On the other hand, $R H$ is relatively more significant climate variable than $T_{a}$ to estimate $E T_{a}$ more accurately in a semi-arid region (Figure $5 \mathrm{c}$ ). Moreover, the commonly used Hargreaves-Samani method [90] for $E T_{o}$ prediction would not provide reliable $E T_{o}$ estimates in a semi-arid region, as the method calculates $E T_{o}$ based on $T_{a}$ and $R_{a}$ only. The $R_{a}$, however, is independent of $R_{S}$ (Equation (4)), which is the most critical climate variable to estimate $E T_{0}$ in a semi-arid region, as shown in Figure 5c. Besides, the Hargreaves-Samani method does not account for the effect of $R H$, which is nonnegligible in $E T_{0}$ estimates, as is evident from Figure 5a.

$R_{S}$ was recently used as a surrogate variable to reduce the uncertainty of $E T_{o}$ projection data [91]. This can be justified by the findings from Figure 5a, in which $R_{s}$ displayed a more profound impact on $E T_{o}$ than the other forcing variables. On the other hand, the mean annual temperature was used by Hartmann et al. [17] as a proxy for $E T_{o}$ in assessing aquifer recharge sensitivity to climate variability based on the argument that $R_{n}$ is temperature-dependent and temperature is the best-understood and most common climatic variable for large-scale hydrological models. Similarly, a computationally simple method of Berti et al. [16] that relies only on $T_{a}$ was reported to be the best alternative method to the FAO56 PME in describing spatiotemporal characteristics of $E T_{0}$ in different sub-regions of mainland China [13]. Such assumptions [17] and conclusions [13], however, should be made with caution in $E T_{o}$ calculations, especially for semi-arid regions, as the ML analysis unveiled that $R_{s}$ (as part of $R_{n}$ in Equation (1)) is more important than $T_{a}$ in $E T_{o}$ prediction. Moreover, Figure A6 revealed that the statistical correlation between $R_{S}$ and $T_{a}$ is weak with $R^{2}<0.6$. Thus, the use of $T_{a}$ as a proxy for $E T_{o}$ is questionable for the semi-arid region.

Gong et al. [92] noted that although the order of importance of climate variables on $E T_{0}$ (computed by the FAO56 PME) varied with season and region in their study, $E T_{0}$ in general was most sensitive to $R H$, followed by $R_{s}, T_{a}$ and $u_{2}$. The authors used time-histories of daily $T_{a}, u_{2}, R H$, and daily sunshine duration. In our analysis, however, measured climate variables were available at the 15 -min intervals, including also $R_{s}$ and $P$. Unlike the general conclusion by Gong et al. [92], our ML-based feature importance calculations in Figure 5a revealed that $R_{s}$ and $T_{a}$ were more critical than $R H$ on $E T_{o}$ estimates. 


\subsection{What Are the New Insights from the NGBoost-XGBoost That Can Not Be Obtained from Other ML Models?}

Interestingly, we found many instances where the ML model shows tendency to predict higher $E T_{a}$ (represented by higher Shapley value on the x-axis) when $R H$ is relatively high (represented as red dots) in Figure 5c. Such findings were also reported by Yan and Shugart [93] from $E T_{a}$ measurements by the EC method. High $E T_{a}$ at high $R H$ could be attributed, for example, to high air-vapor uptake by water deficit soil and vegetation in hot and humid days, which are subsequently released back into air due to evaporation from soil and transpiration from vegetation; or evaporation from saturated soil and transpiration from vegetation in high $R H$ conditions following rain events; or evaporation from moist soil on a cold day following rain events. Unlike the ML-based modeling, the dynamics between soil moisture, vegetation water uptake, rain events, $T_{a}, R H$ and $E T_{a}$ cannot be captured by one-to-one correlation, as shown in Figure A6. Additionally, Figure 6 shows that, in certain situations, the model generates low $E T_{a}$ predictions despite high $E T_{o} \&$ low $R H$ measures, which could be driven by critical moisture deficiency in the soil, especially in hot and dry summer. This could be a serious concern in future, as for a $2{ }^{\circ} \mathrm{C}$ of global warming, most of Texas was projected to experience more than a doubling in the number of days above $38^{\circ} \mathrm{C}$ [94]. Such more frequent high $T_{a}$ over extended periods could increase the soil moisture deficiency, and decrease aquifer recharge and springs flow, which could affect sustainability of groundwater for consumptive water uses and environmental flows.

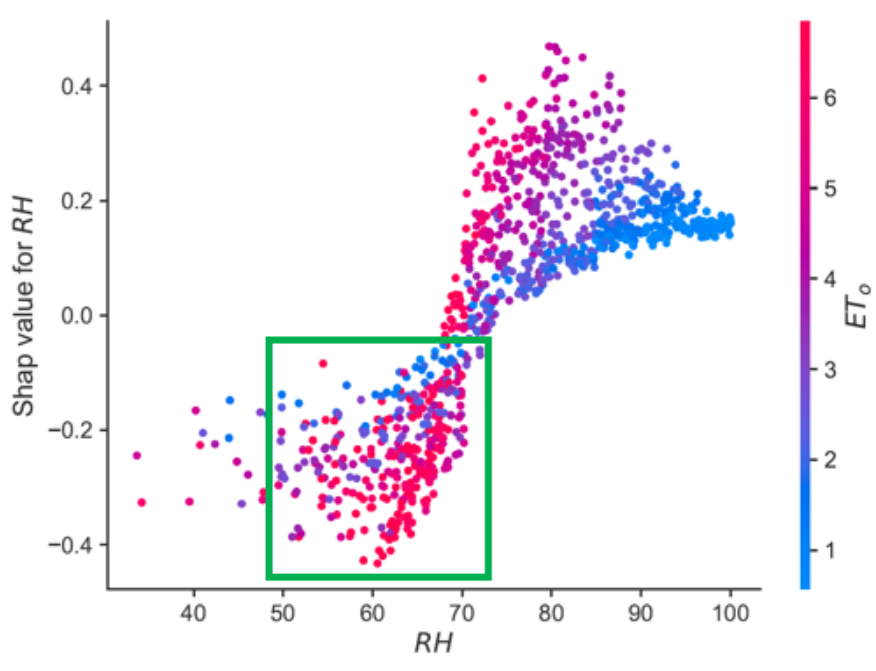

(a) $R H$ dependence plot with $E T_{o}$ interaction.

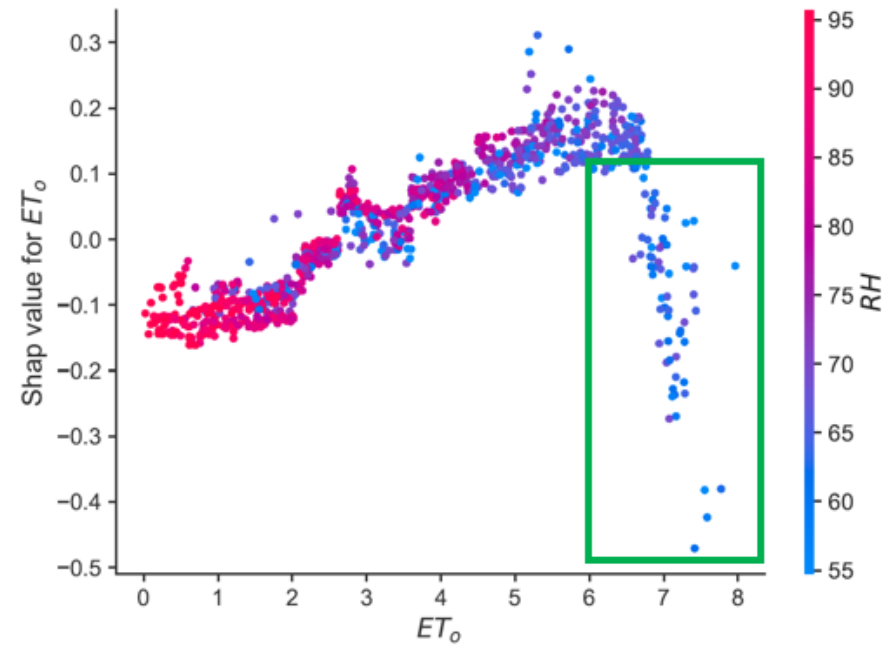

(b) $E T_{o}$ dependence plot with $R H$ interaction.

Figure 6. Dependence \& interaction plots revealing the interrelationship between $R H, E T_{0}$, and the corresponding Shap values. The Shap values represent the model's behavior to either push the $E T_{a}$ value higher or lower. A higher Shap value means that the model is trying to produce a higher $E T_{a}$ prediction, and vice-versa. The green boxes highlight the regions where low $R H$ values correspond to high $E T_{o}$ values but low $E T_{a}$ predictions, which could be attributed to soil moisture deficiency.

\section{Conclusions}

We developed and presented a novel probabilistic hybrid NGBoost-XGBoost model to simultaneously predict $E T_{a}, E_{s w}$, and $E T_{o}$ from the standard local hydroclimatic data. Different from other ML models, the proposed hybrid ML model is able to produce point predictions as well as a probability distribution over the entire outcome space to quantify uncertainties associated with ET predictions. The proposed hybrid model could provide practitioners with a better understanding of the uncertainty in the $E T_{o}, E_{s w}$, and $E T_{a}$ predictions without compromising the accuracy of the predictions. Our results showed that the hybrid NGBoost-XGBoost ML model successfully predicted the FAO56 PME-computed $E T_{o}$, and measured $E_{s w}$ and $E T_{a}$, in which $\geq 89.9 \%$ of the target data points were within 
the $95 \%$ prediction interval of the model, and $R^{2}$ values for the point predictions were $0.994,0.750$, and 0.801 , respectively, using data from the model testing period. These results exhibit that the proposed hybrid ML model is a reliable and robust alternative method to predict $E T_{0}, E_{s w}$, and $E T_{a}$ from local climate data, without implementing net solar radiation calculations required by the FAO56 PME, coping with uncertainties in $E_{s w}$ estimates using evaporation pans, or having expensive EC tower setups for $E T_{a}$ measurements.

We also demonstrated that the Shapley method, based on a game theory approach, identified the order of importance of hydroclimatic features on $E T_{0}, E_{s w}$, and $E T_{a}$ predictions, and we compared and contrasted these findings against the findings in the literature, which were typically performed by sensitivity and correlation analyses. The idea behind this analysis was to explain the prediction of an instance by computing the contribution of each feature to the prediction. Our analysis revealed that the shortwave solar radiation, air temperature, and relative humidity are the most critical features for the daily $E T_{0}$ predictions, whereas the surface water temperature, relative humidity, and the month are the most critical features for the daily $E_{s w}$ predictions, and the shortwave solar radiation, month, and relative humidity are the most critical features for the daily $E T_{a}$ predictions in the semi-arid region.

Author Contributions: H.B. and J.W. performed database management, data quality checks, and FAO56 PME and MF calculations. D.C. developed the predictive ML models and performed the feature analysis. All authors are involved in conceptualization, analyzed the results, and wrote, reviewed, and edited the manuscript. All authors have read and agreed to the published version of the manuscript.

Funding: This research received no external funding.

Institutional Review Board Statement: Not applicable.

Informed Consent Statement: Not applicable.

Data Availability Statement: The data presented in this study, along with the codes, are openly available on Code Ocean at https:/ / doi.org/10.24433/CO.9965585.v1, accessed on 18 February 2021.

Acknowledgments: The authors would like to thank to Newfel Mazari and Marcus Gary of EAA for their help with acquisition of climate data from EAA weather stations; Ned Troshanov and Sarah Eason of EAA for their help with preparation of the location map; John Zhu of TWDB in Austin, TX for providing us with the raw daily pan evaporation data and follow-up discussions; and Tara Bongiovanni of BEG in Austin, TX for sharing with us the daily actual evapotranspiration data from the Eddy covariance tower in Camp Bullis, TX.

Conflicts of Interest: The authors declare no conflict of interest.

\section{Abbreviations}

Commonly used abbreviations in the paper:

$\begin{array}{ll}E_{p} & \text { Pan evaporation } \\ E T & \text { Evapotranspiration } \\ E T_{o} & \text { Reference crop evapotranspiration } \\ E T_{a} & \text { Actual evapotranspiration } \\ E T_{p} & \text { Potential evapotranspiration } \\ E_{s w} & \text { Surface Water Evaporation } \\ P & \text { Atmospheric pressure } \\ R_{s} & \text { Shortwave solar radiation } \\ R H & \text { Relative humidity } \\ T_{a} & \text { Air temperature } \\ T_{s w} & \text { Surface water temperature } \\ u_{2} & \text { wind speed at } 2 \text { m above the ground surface } \\ \text { BCRAGD } & \text { Bandera County River Authority and Groundwater District's office } \\ \text { CBS } & \text { Camp Bullis, Savanna } \\ \text { EC } & \text { Eddy covariance }\end{array}$




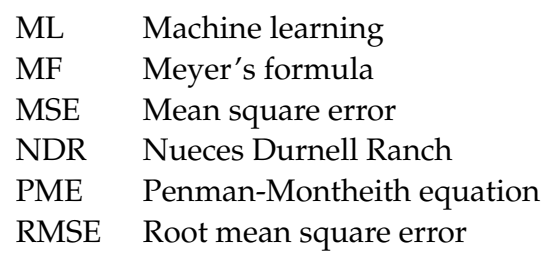

\section{Appendix A. Hydroclimotogical Data}

Appendix A.1. Nueces Durnell Ranch (NDR) Weather Station

For hourly- $E T_{o}$ calculations, hourly-averaged $T_{a}, P, R H$, and $u_{2}$ and hourly-summed $R_{s}$ at the NDR station, shown in Figure A1, were used as input in Equation (1). The total number of missing hourly records at this site was less than $0.1 \%$, which were filled in by linear interpolation. The NDR weather station was selected in the analysis due to its proximity to Uvalde County, TX, where monthly representative cloud cover data were obtained.
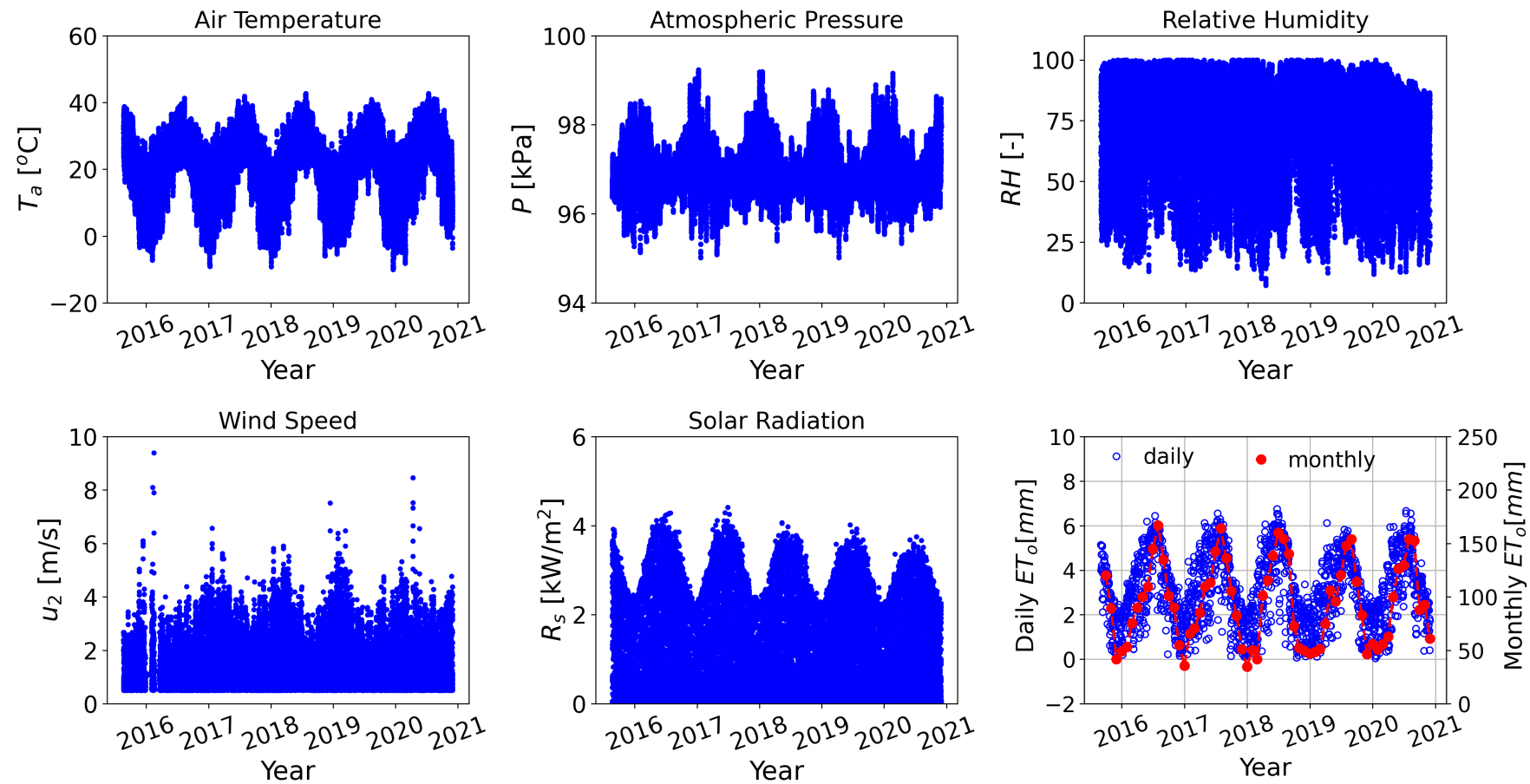

Figure A1. Hourly climate data and FAO56 PME-computed $E T_{0}$ at the NDR weather station.

Appendix A.2. Bandera County River Authority and Groundwater District's office (BCRAGD) Weather Station

The closest weather station to Lake Ingram is located at the Bandera County River Authority and Groundwater District's office. The same set of local climate data at the BCRAGD station was available for the same period at the NDR station. The total number of missing hourly data was less than $0.1 \%$, which were filled by linear interpolation. 

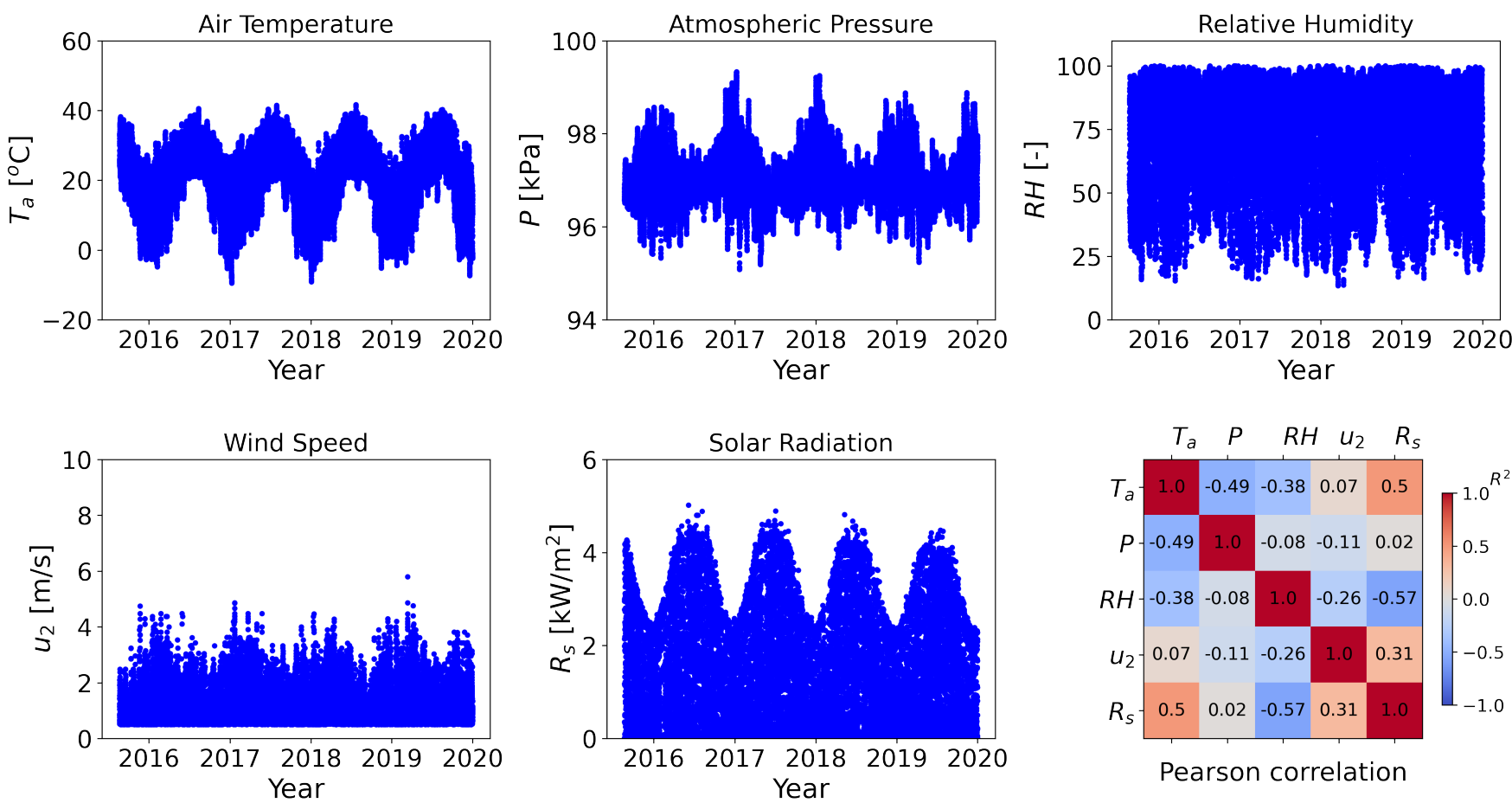

Figure A2. Hourly climate data and statistical correlations among them at the BCRAGD weather station.

Appendix A.3. Camp Bullis Site (CBS) Weather Station

$E T_{a}$ measurements were obtained from the EC tower at Savanna, Well 10 near Camp Bullis, TX. Instruments were installed approximately $1.2 \mathrm{~m}$ above the height of the vegetation. Vegetation at the EC tower is open oak savanna. Daily $E T_{a}$ data were available from $5 / 4 / 2016$ to $1 / 21 / 2019$. Less than $0.1 \%$ daily $E T_{a}$ measurements were missing, which were filled in by linear interpolation.
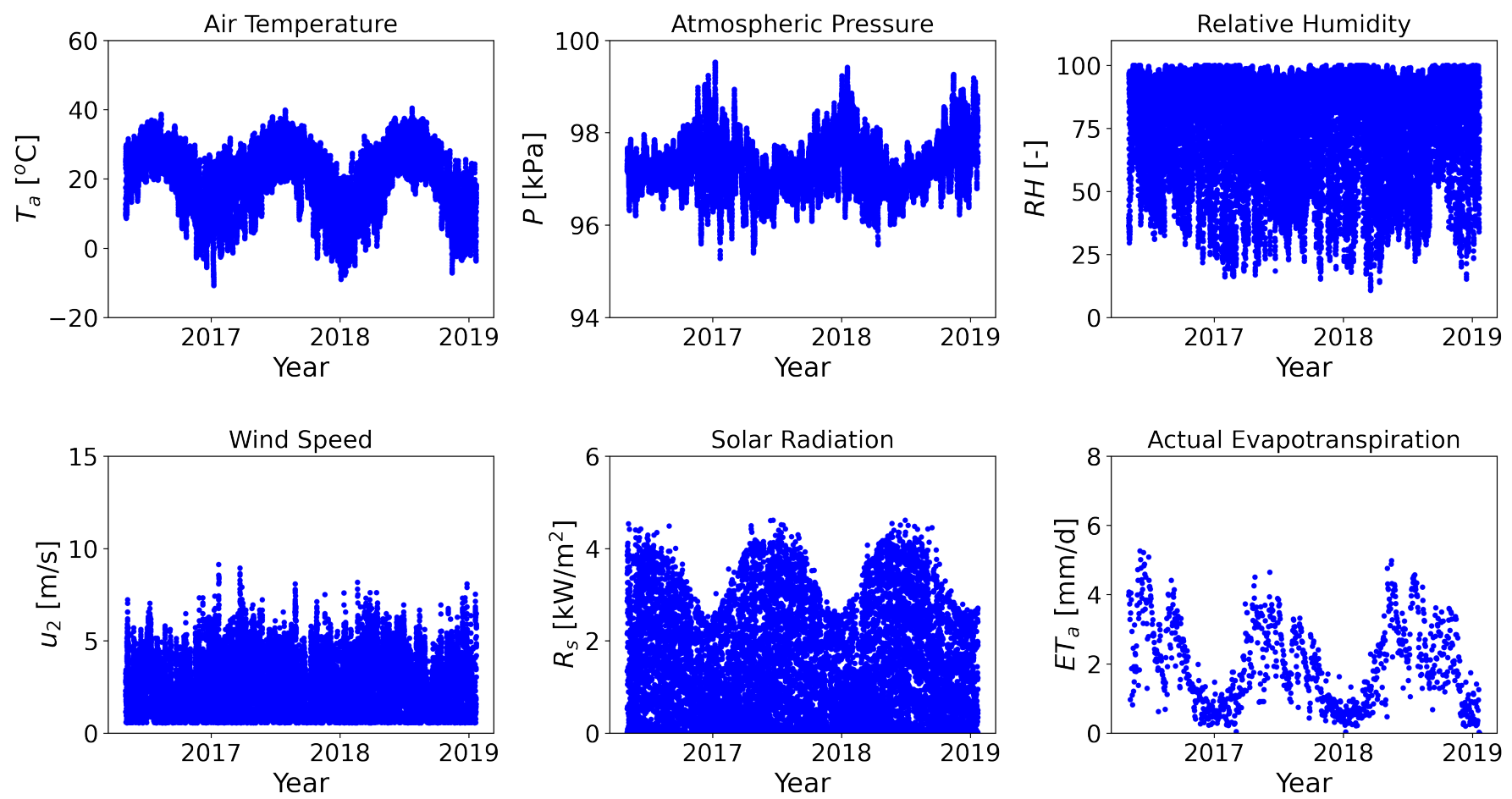

Figure A3. Hourly climate data from the EAA's weather station at Savanna, Well 10, and daily $E T_{a}$ measurements from the EC tower. 


\section{Appendix A.4. Surface Water Data}

Daily and monthly surface water evaporation data closest to the NDR site were obtained from Ingram Lake in Texas. Daily pan evaporation measurements $\left(E_{p}\right)$ from 9/1/2015 to 12/31/2019 were taken by the Texas Water Development Board (TWDB). 1.9\% of these measurements were missing, which were filled in by linear interpolation. These measurements were upscaled to daily lake evaporation totals $\left(E_{s w}\right)$ using monthly-varying pan coefficients developed by the TWDB. However, sporadically extremely high and low $E_{s w}$ values, shown in Figure A4a, were found to be quantitatively inconsistent with the climatic data $\left(T_{a}, R_{s}\right.$, and $\left.R H\right)$ trends at the BCRAGD station, provided in Appendix A.2. Therefore, this time series is regarded as anomalous. Such anomalies are quite common in $E_{p}$ measurements due to birds drinking from the pan, debris falling in, or water splashing out [95]. Subsequently, these anomalies are carried into the daily $E_{s w}$ data, but largely smoothed out in monthly-averaged $E_{s w}$. Because the ML model was run with daily $E_{s w}$ data here, a 7-day rolling median function was used to reduce the noise and outliers in the daily $E_{s w}$ data (Figure A4a). Monthly $E_{s w}$, derived from daily $E_{s w}$ (Figure A4) were then used to determine the suitability of the MFs to predict the monthly $E_{s w}$ at Ingram Lake.

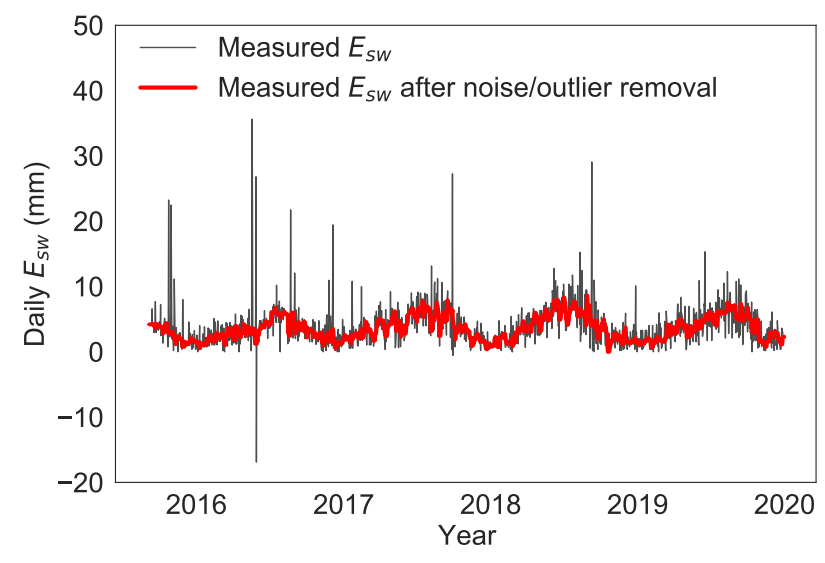

(a) Lake evaporation

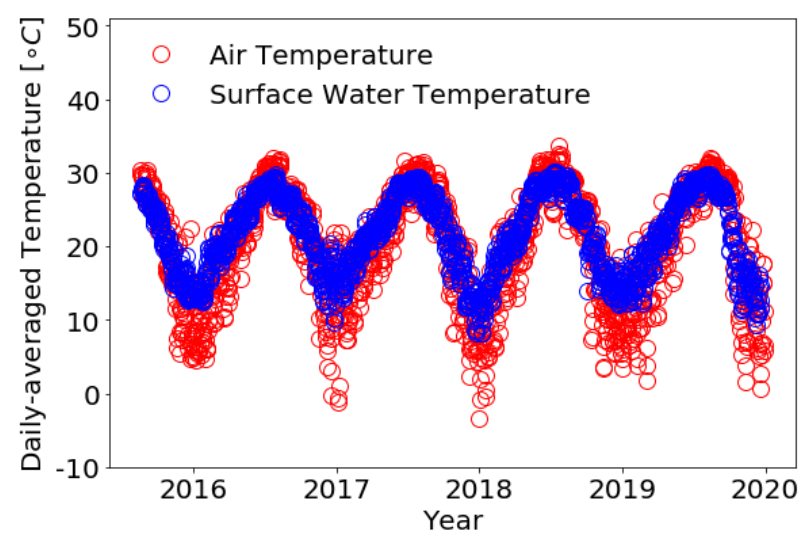

(b) Surface water and air temperature

Figure A4. Surface water measurements closest to the NDR weather station. Surface water temperatures at 15-min intervals were obtained from Frio river in Concan, and daily lake evaporation data were obtained from Ingram Lake in Texas.

The daily and monthly $E_{s w}$ rely on surface water temperature, $T_{s w}[34,35]$. The closest gauging station, with the surface water temperature data from 9/1/2015 to 12/31/2019 at the 15-min (or 1-h) intervals, to Ingram Lake is the U.S. Geological Survey Station (USGS 08195000) located at the Frio River in Concan, TX. The Frio River at the USGS 08195000 and Ingram Lake are small-size surface water bodies fed by groundwater from the Trinity aquifer. Therefore, $T_{s w}$ from the Frio river were used in MF-based $E_{s w}$ calculations at Ingram Lake. Daily-averaged $T_{s w}$ are shown in Figure A4b. Because the Frio river is a groundwater-fed river, $T_{s w} \geq T_{a}$ in winter; whereas, $T_{s w} \leq T_{a}$ in summer. $0.26 \%$ of daily $T_{s w}$ were missing, which were filled in by linear interpolation.

\section{Appendix B. NGBoost and XGBoost Models}

\section{Appendix B.1. Natural Gradient Boosting (NGBoost)}

NGBoost is a supervised learning algorithm with generic probabilistic prediction capability. A probabilistic prediction produces a full probability distribution over the entire outcome space; thus, enabling the users to quantify the uncertainties in the construction cost predictions produced by the model. In standard point prediction settings, the object of interest is an estimate of the scalar function $E(y \mid x)$, where $x$ is the feature vector and $y$ is the prediction target, without accommodating uncertainty estimates. In contrast, under a probabilistic prediction setting, a probabilistic forecast with probability distribution $P_{\theta}(y \mid x)$ is produced by predicting the parameters $\theta$. NGBoost can perform probabilistic forecast 
with flexible tree-based models, given that NGBoost is designed to be scalable and modular with respect to the base learner (e.g., decision trees), probability distribution parameter (e.g., normal, Laplace, etc.), scoring rule (e.g., Maximum Likelihood Estimation). As shown in Figure A5, the input feature vector $x$ in the hybrid NGBoost model is passed on to the base learners (decision trees) to produce a probability distribution of the predictions $P_{\theta}(y \mid x)$ over the entire outcome space $y$. The models are then optimized by scoring rule $S\left(P_{\theta}, y\right)$ using a maximum likelihood estimation function that yields calibrated uncertainty and point predictions.

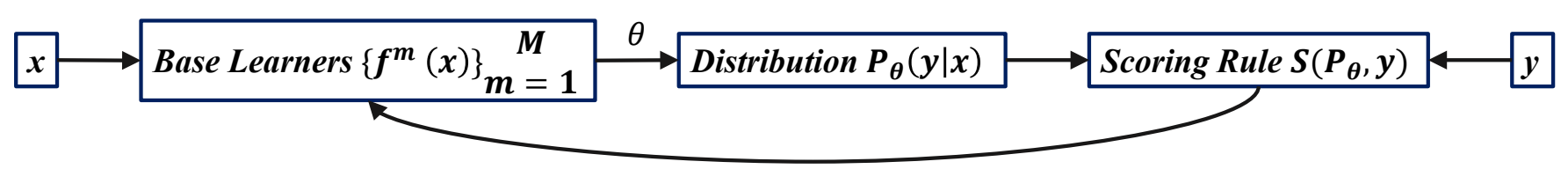

\section{Fit Natural Gradients $\widetilde{\nabla}_{\theta}$}

Figure A5. Conceptual representation of the NGBoost model (Source: Duan et al. [77]).

\section{Appendix B.2. eXtreme Gradient Boosting (XGBoost)}

Extreme gradient boosting (XGBoost), proposed by Chen \& Guestrin [78], is a variant of tree-based boosting algorithm. Conceptually, XGBoost learns the functional relationship $f$ between the features $X$ and target $Y$ through an iterative process in which the individual trees are sequentially trained on the residuals from the previous tree. Mathematically the predictions from the trees can be expressed as

$$
\widehat{Y}=\phi(X)=\frac{1}{n} \sum_{k=1}^{n} f_{k}(X)
$$

where $\widehat{Y}$ is the predicted $E_{c}, 1 \leq k \leq n$, and $n$ is the total number of functions learnt by the $n$ number of trees. The following regularized objective $\mathcal{L}(\phi)$ is minimized to learn the set of functions $f_{k}$ used in the model

$$
\begin{aligned}
\mathcal{L}(\phi) & =\sum_{i} l\left(\hat{y}_{i}, y_{i}\right)+\sum_{k} \Omega\left(f_{k}\right) \\
\text { where } \Omega\left(f_{k}\right) & =\gamma T+\frac{1}{2} \lambda\|w\|^{2},
\end{aligned}
$$

where $l$ is a differentiable convex loss function that measures the difference between $\hat{y}_{i}$ (prediction) and $y_{i}$ (target). $\Omega$ is an extra regularization term that penalizes the growing of more trees in the model to prevent complexity and thus, reduce overfitting. $\gamma$ is the complexity of each leaf, $T$ is the number of leaves in a tree, $\lambda$ is a penalty parameter, and $\|w\|$ is the vector of scores on the leaves. Note that if the regularization parameter $\Omega$ is set to zero, the objective falls back to the traditional gradient tree boosting. For more detailed information on how the model is trained in an additive manner to optimize Equation (A2), the reader is referred to Chen \& Guestrin [78]. 


\section{Appendix C. Statistical Correlations among Daily Variables}

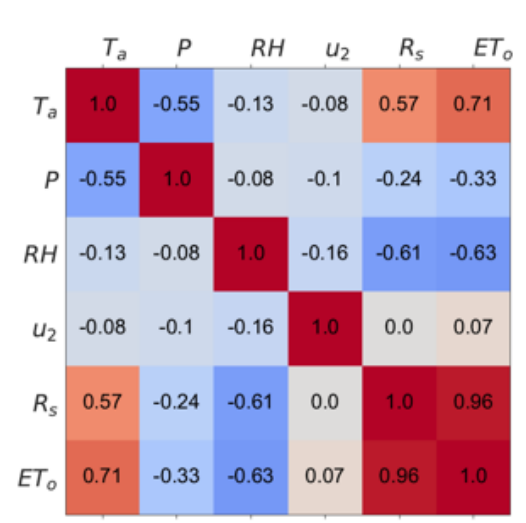

(a) $E T_{o}$.

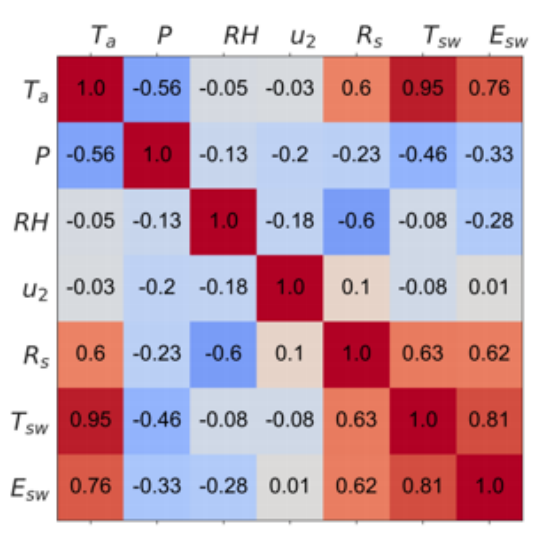

(b) $E_{s w}$.

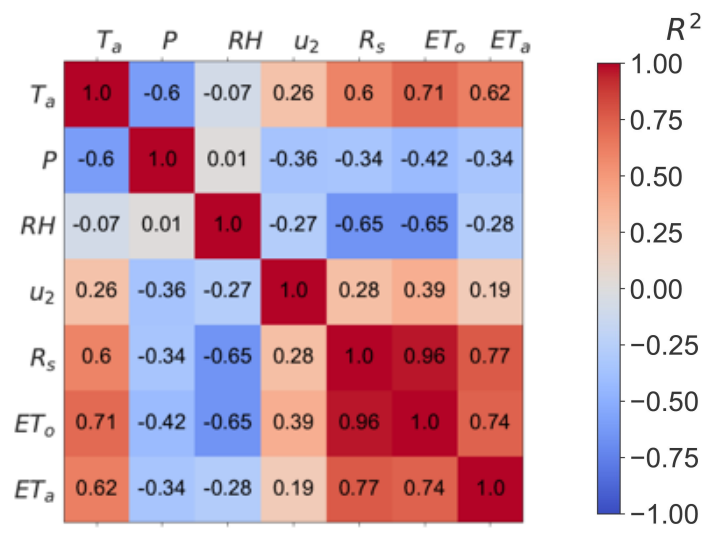

(c) $E T_{a}$.

Figure A6. Correlation map between daily climatic variables and (a) the reference evapotranspiration at the NDR site, (b) lake evaporation at Ingram Lake, and (c) and actual evapotranspiration at the CBS site.

\section{References}

1. Heilman, J.L.; McInnes, K.J.; Kjelgaard, J.F.; Owens, M.K.; Schwinning, S. Energy balance and water use in a subtropical karst woodland on the Edwards Plateau, Texas. J. Hydrol. 2009, 373, 426-435. [CrossRef]

2. Gokmen, M.; Vekerdy, Z.; Lubczynski, M.W.; Timmermans, J.; Batelaan, O.; Verhoef, W. Assessing groundwater storage changes using remote sensing-based evapotranspiration and precipitation at a large semiarid basin scale. J. Hydrometeorol. 2013, 14, 1733-1753. [CrossRef]

3. Glenn, E.P.; Scott, R.L.; Nguyen, U.; Nagler, P.L. Wide-area ratios of evapotranspiration to precipitation in monsoon dependent semiarid vegetation communities. J. Arid Environ. 2015, 117, 84-95. [CrossRef]

4. Wu, W.Y.; Lo, M.H.; Wada, Y.; Famiglietti, J.S.; Reager, J.T.; Yeh, P.J.F.; Ducharne, A.; Yang, Z.L. Divergent effects of climate change on future groundwater availability in key mid-latitude aquifers. Nat. Commun. 2020, 11, 3710. [CrossRef]

5. Hauwert, N.; Sharp, J.M. Measuring autogenic recharge over a karst aquifer utilizing Eddy covariance evapotranspiration. J. Water Resour. Prot. 2014, 6, 869-879. [CrossRef]

6. Xie, Y.; Crosbie, R.; Yang, J.; Wu, J.; Wang, W. Usefulness of soil moisture and actual evapotranspiration data for constraining potential groundwater recharge in semiarid regions. Water Resour. Res. 2018, 54, 4929-4945. [CrossRef]

7. Allen, R.G.; Pereira, L.S.; Raes, D.; Smith, M. Crop Evapotranspiration-Guidelines for Computing Crop Water Requirements; FAO Irrigation and Drainage Paper 56; FAO: Rome, Italy, 1998; ISBN 92-5-104219-5.

8. Stöckle, C.O.; Kjelgaard, J.; Bellocchi, G. Evaluation of estimated weather data for calculating Penman-Monteith reference crop evapotranspiration. Irrig. Sci. 2004, 23, 39-46. [CrossRef]

9. Scheff, J.; Frierson, D.M.W. Scaling potential evapotranspiration with greenhouse warming. J. Clim. 2014, 27, 1539-1558. [CrossRef]

10. Chiarelli, D.D.; Passera, C.; Rosa, L.R.; Davis, K.F.; D'Odorico, P.; Rulli, M. The green and blue crop water requirement WATNEEDS model and its global gridded outputs. Sci. Data 2020, 7, 273. [CrossRef]

11. Ndiaye, P.; Bodian, A.; Diop, L.; Deme, A.; Dezetter, A.; Djaman, K.; Ogilvie, A. Trend and sensitivity analysis of reference evapotranspiration in the Senegal river basin using NASA meteorological data. Water 2020, 12, 1957. [CrossRef]

12. Irmak, S.; Irmak, A.; W, J.J.; Howell, T.A.; Jacobs, J.M.; Allen, R.G. Predicting daily net radiation using minimum climatological data. J. Irrig. Drain. Eng. 2003, 129, 256-269. [CrossRef]

13. Peng, L.; Feng, H. The best alternative for estimating reference crop evapotranspiration in different sub-regions of mainland China. Sci. Rep. 2017, 7, 5458. [CrossRef] [PubMed]

14. Fan, J.; Yue, W.; Wu, L.; Zhang, F.; Cai, H.; Wang, X.; Lu, X.; Xiang, Y. Evaluation of SVM, ELM and four tree-based ensemble models for predicting daily reference evapotranspiration using limited meteorological data in different climates of China. Agric. For. Meteorol. 2018, 263, 225-241. [CrossRef]

15. Celestin, S.; Qi, F.; Li, R.; Yu, T.; Cheng, W. Evaluation of 32 simple equations against the Penman-Monteith method to estimate the reference evapotranspiration in the Hexi corridor, Northwest China. Water 2020, 12, 2772. [CrossRef]

16. Berti, A.; Tardivo, G.; Chiaudani, A.; Rech, F.; Borin, M. Assessing reference evapotranspiration by the Hargreaves method in north-eastern Italy. Agric. Water Manag. 2017, 140, 20-25. [CrossRef]

17. Hartmann, A.; Gleesonc, T.; Wadae, Y.; Wagener, T. Enhanced groundwater recharge rates and altered recharge sensitivity to climate variability through subsurface heterogeneity. Proc. Natl. Acad. Sci. USA 2017, 114, 2842-2847. [CrossRef] 
18. Dewes, C.F.; Rangwala, I.; Barsugli, J.J.; Hobbins, M.T.; Kumar, S. Drought risk assessment under climate change is sensitive to methodological choices for the estimation of evaporative demand. PLoS ONE 2017, 12, e0174045. [CrossRef]

19. Naumann, G.; Alfieri, L.; Wyser, K.; Mentaschi, L.; Betts, R.; Carrao, H.; Spinoni, J.; Vogt, J.; Feyen, L. Global changes in drought conditions under different levels of warming. Geophys. Res. Lett. 2018, 45, 3285-3296. [CrossRef]

20. Vicente-Serrano, S.M.; Beguería, S.; López-Moreno, J.I. A multiscalar drought index sensitive to global warming: The standardized precipitation evapotranspiration index. J. Clim. 2010, 23, 1696-1718. [CrossRef]

21. Cook, B.I.; Smerdon, J.E.; Seager, R.; Coats, S. Global warming and 21st century drying. Clim. Dyn. 2014, 43, 2607-2627. [CrossRef]

22. Greve, P.; Ukkola, A.M.; Roderick, M.L.; Wada, A.M. The aridity Index under global warming. Environ. Res. Lett. 2019, 14, 124006. [CrossRef]

23. Paltineanu, C.; Mihailescu, I.; Seceleanu, I.; Dragota, C.; Vasenciuc, F. Using aridity indices to describe some climate and soil features in Eastern Europe: A Romanian case study. Theor. Appl. Climatol. 2007, 90, 263-274. [CrossRef]

24. Park, C.; Jeong, S.; Joshi, M.; Osborn, T.J.; Ho, C.H.; Piao, S.; Chen, D.; Liu, J.; Yang, H.; Park, H.; et al. Keeping global warming within $1.5^{\circ} \mathrm{C}$ constrains emergence of aridification. Nat. Clim. Chang. 2018, 8, 70-74. [CrossRef]

25. Nouri, M.; Bannayan, M. Spatiotemporal changes in aridity index and reference evapotranspiration over semi-arid and humid regions of Iran: Trend, cause, and sensitivity analyses. Theor. Appl. Climatol. 2019, 136, 1073-1084. [CrossRef]

26. Pereira, L.S.; Allen, R.G.; Smith, M.; Raes, D. Crop evapotranspiration estimation with FAO56: Past and future. Agric. Water Manag. 2015, 147, 4-20. [CrossRef]

27. Corbari, C.; Ravazzani, G.; Galvagno, M.; Cremonese, E.; Mancini, M. Assessing crop coefficients for natural vegetated areas using satellite data and Eddy covariance stations. Sensors 2017, 17, 2664. [CrossRef]

28. Zanotelli, D.; Montagnani, L.; Andreotti, C.; Tagliavini, M. Evapotranspiration and crop coefficient patterns of an apple orchard in a sub-humid environment. Agric. Water Manag. 2019, 226, 105756. [CrossRef]

29. van der Kamp, G.; Keir, D.; Evans, M. Long-term water level changes in closed-basin lakes of the Canadian prairies. Can. Water Resour. J. 2008, 33, 23-38. [CrossRef]

30. Wang, W.; Lee, X.; Xiao, W.; Liu, S.; Schultz, N.; Wang, Y.; Zhang, M.; Zhao, L. Global lake evaporation accelerated by changes in surface energy allocation in a warmer climate. Nat. Geosci 2018, 11, 410-414. [CrossRef]

31. Vercauteren, N.; Bou-Zeid, E.; Huwald, H.; Parlange, M.B.; Brutsaert, W. Estimation of wet surface evaporation from sensible heat flux measurements. Water Resour. Res. 2009, 45, 735-742. [CrossRef]

32. Roderick, M.L.; Hobbins, M.T.; Farquhar, G. Pan evaporation trends and the terrestrial water balance. II. Energy balance and interpretation. Geogr. Compass. 2009, 3, 761-780. [CrossRef]

33. Boughton, W. The Australian water balance model. Environ. Modell. Softw. 2004, 19, 943-956. [CrossRef]

34. Xu, C.Y.; Sing, V.P. Cross comparison of empirical equations for calculating potential evapotranspiration with data from Switzerland. Water Resour. Manag. 2002, 16, 197-219. [CrossRef]

35. Burn, D.H.; Hesch, N.M. A comparison of trends in potential and pan evaporation for the Canadian Ppairies. Can. Water Resour. J. 2006, 31, 173-184. [CrossRef]

36. Tanny, J.; Cohen, S.; Berger, D.; Teltch, B.; Mekhmandarov, Y.; Bahar, M.; Katul, G.; Assouline, S. Evaporation from a reservoir with fluctuating water level: Correcting for limited fetch. J. Hydrol. 2011, 404, 146-156. [CrossRef]

37. Xiao, K.; Griffis, T.J.; Baker, J.M.; Bolstad, P.V.; Erickson, M.D.; Leed, X.; Wood, J.D.; Hu, C.; Nieberg, J.L. Evaporation from a temperate closed-basin lake and its impact on present, past, and future water level. J. Hydrol. 2018, 561, 59-75. [CrossRef]

38. Fu, G.; Liu, C.; Chen, S.; Hong, J. Investigating the conversion coefficients for free water surface evaporation of different evaporation pans. J. Hydrol. 2004, 18, 2247-2262. [CrossRef]

39. Tanny, J.; Cohen, S.; Assouline, S.; Lange, F.; Grava, A.; Berger, D.; Teltch, B.; Parlange, M. Evaporation from a small water reservoir: Direct measurements and estimates. J. Hydrol. 2008, 351, 218-229. [CrossRef]

40. Zhang, Y.; Peña-Arañcibia, J.L.; McVicar, T.R.; Chiew, F.H.S.; Vaze, J.; Liu, C.; Lu, X.; Zheng, H.; Wang, Y.; Liu, Y.Y.; et al. Multi-decadal trends in global terrestrial evapotranspiration and its components. Sci. Rep. 2016, 6, 19124. [CrossRef]

41. Burba, G. Eddy Covariance Method for Scientific, Industrial, Agricultural and Regulatory Applications: A Field Book on Measuring Ecosystem Gas Exchange and Areal Emission Rates; Li-Cor Biosciences: Lincoln, NE, USA, 2013.

42. Vesala, T.; Huotari, J.; Rannik, U.; Suni, T.; Smolander, S.; Sogachev, A.; Launiainen, S.; Ojala, A. Eddy covariance measurements of carbon exchange and latent and sensible heat fluxes over a boreal lake for a full open-water period. J. Geophys. Res. 2006, 111, D11101. [CrossRef]

43. Wang, S.; Pan, M.; Mu, Q.; Shi, X.; Mao, J.; Brummer, C.; Jassal, R.S.; Praveena, K.; Li, J.; Black, T.A. Comparing evapotranspiration from Eddy covariance measurements, water budgets, remote sensing, and land surface models over Canada. J. Hydrometeorol. 2015, 16, 1540-1560. [CrossRef]

44. Wilson, K.; Hanson, P.J.; Mulholland, P.J.; Baldocchi, D.D.; Wullschleger, S.D. A comparison of methods for determining forest evapotranspiration and its components: Sap-flow, soil water budget, Eddy covariance and catchment water balance. Agric. Forest Meteorol. 2001, 106, 153-168. [CrossRef]

45. Zitouna-Chebbi, R.; Prévot, L.; Chakhar, A.; Marniche-Ben Abdallah, M.; Jacob, F. Observing actual evapotranspiration from flux tower Eddy covariance measurements within a Hilly watershed: Case Study of the Kamech site, Cap Bon Peninsula, Tunisia. Atmosphere 2018, 9, 68. [CrossRef] 
46. Lascano, R.J.; van Bavel, C.H.M. Explicit and recursive calculation of potential and actual evapotranspirations. Agron. J. 2007, 99, 585-590. [CrossRef]

47. Li, S.; Kang, S.; Zhang, L.; Zhang, J.; Du, T.; Tong, L.; Ding, R. Evaluation of six potential evapotranspiration models for estimating crop potential and actual evapotranspiration in arid regions. J. Hydrol. 2016, 543, 450-461. [CrossRef]

48. Wang, T.; Zlotnik, V.A. A complementary relationship between actual and potential evapotranspiration and soil effects. J. Hydrol. 2012, 456-457, 146-150. [CrossRef]

49. Morton, F.I. Potential evaporation and river basin evaporation. J. Hydraul. Div. Am. Soc. Civ. Eng. 1965, 102, 275-291. [CrossRef]

50. Milly, P.C.D.; Dunne, K.A. Potential evapotranspiration and continental drying. Nat. Clim. Chang. 2016, 6, 946-951. [CrossRef]

51. Liu, Y.; Hao, L.; Zhou, D.; Pan, C.; Liu, P.; Xiong, Z.; Sun, G. Identifying a transition climate zone in an arid river basin using the evaporative stress index. Nat. Hazards Earth Syst. Sci. 2019, 19, 2281-2294. [CrossRef]

52. Choi, M.; Jacobs, J.M.; Anderson, M.C.; Bosch, D.D. Evaluation of drought indices via remotely sensed data with hydrological variables. J. Hydrol. 2013, 476, 265-273. [CrossRef]

53. Yao, A.Y.M. Agricultural potential estimated from the ratio of actual to potential evapotranspiration. Agric. Meteorol. 1974, 13, 405-417. [CrossRef]

54. Anderson, M.C.; Zolin, C.A.; Sentelhas, P.C.; Hain, C.R.; Semmens, K.; Yilmaz, M.T.; Gao, F.; Otkin, J.A.; Tetrault, R. The Evaporative Stress Index as an indicator of agricultural drought in Brazil: An assessment based on crop yield impacts. Remote Sens. Environ. 2016, 174, 82-99. [CrossRef]

55. Lingling, Z.; Jun, X.; Chong-yu, X.; Zhonggen, W.; Leszek, S.; Cangrui, L. Evapotranspiration estimation methods in hydrological models. J. Geogr. Sci. 2013, 23, 359-369. [CrossRef]

56. Wu, L.; Fan, J. Comparison of neuron-based, kernel-based, tree-based and curve based machine learning models for predicting daily reference evapotranspiration. PLOS ONE 2019, 14, e0217520. [CrossRef]

57. Lifeng, W.; Youwen, P.; Junliang, F.; Wang, Y. Machine learning models for the estimation of monthly mean daily reference evapotranspiration based on cross-station and synthetic data. Hydrol. Process. 2019, 50, 1730-1750. [CrossRef]

58. Sattari, M.; Apaydin, H.; Shamshirband, S. Performance evaluation of deep learning-based gated recurrent units (GRUs) and tree-based models for estimating ETo by using limited meteorological variables. Mathematics 2020, 8, 972. [CrossRef]

59. Chakraborty, D.; Başağaoğlu, H.; Winterle, J. Interpretable vs. noninterpretable machine learning models for data-driven hydro-climatological process modeling. Expert Syst. Appl. 2021, 170, 114498. [CrossRef]

60. Goyal, M.K.; Bharti, B.; Quilty, J.; Adamowski, J.; Pandey, A. Modeling of daily pan evaporation in sub tropical climates using ANN, LS-SVR, Fuzzy Logic, and ANFIS. Expert Syst. Appl. 2014, 41, 5267-5276. [CrossRef]

61. Lua, X.; Jua, Y.; Wu, L.; Fan, J.; Zhang, F.; Li, Z. Daily pan evaporation modeling from local and cross-station data using three tree-based machine learning models. J. Hydrol. 2018, 566, 668-684. [CrossRef]

62. Alsumaiei, A. Utility of artificial neural networks in modeling pan evaporation in hyper-arid climates. Water 2020, 12, 1508. [CrossRef]

63. Filgueiras, R.; Almeida, T.S.; Mantovani, E.C.; Dias, S.H.B.; InácioFernandes-Filho, E.; Cunha, F.F.; Venancio, L.P. Soil water content and actual evapotranspiration predictions using regression algorithms and remote sensing data. Agric. Water Manag. 2020, 241, 106346. [CrossRef]

64. Nema, M.K.; Khare, D.; Chandniha, S.K. Application of artificial intelligence to estimate the reference evapotranspiration in sub-humid Doon valley. App. Water Sci. 2017, 7, 3903-3910. [CrossRef]

65. Feng, Y.; Cui, N.; Gong, D.; Zhang, Q.; Zhao, L. Evaluation of random forests and generalized regression neural networks for daily reference evapotranspiration modelling. Agric. Water Manag. 2017, 193, 163-173. [CrossRef]

66. Jovic, S.; Nedeljkovic, B.; Golubovic, Z.; Kostic, N. Evolutionary algorithm for reference evapotranspiration analysis. Comput. Electron. Agric. 2018, 150,1-4. [CrossRef]

67. Dou, X.; Yang, Y. Evapotranspiration estimation using four different machine learning approaches in different terrestrial ecosystems. Comput. Electron. Agric. 2018, 148, 95-106. [CrossRef]

68. Mehdizadeh, S. Estimation of daily reference evapotranspiration (ETo) using artificial intelligence methods: Offering a new approach for lagged ETo data-based modeling. J. Hydrol. 2018, 559, 794-812. [CrossRef]

69. Kisi, O.; Alizamir, M. Modelling reference evapotranspiration using a new wavelet conjunction heuristic method: Wavelet extreme learning machine vs wavelet neural networks. Agric. Forest Meteorol. 2018, 263, 41-48. [CrossRef]

70. Tao, H.; Diop, L.; Bodian, A.; Djaman, K.; Ndiaye, P.M.; Yaseen, Z.M. Reference evapotranspiration prediction using hybridized fuzzy model with firefly algorithm: Regional case study in Burkina Faso. Agric. Water Manag. 2018, 208, 140-151. [CrossRef]

71. Sanikhani, H.; Kisi, O.; Maroufpoor, E.; Yaseen, Z.M. Temperature-based modeling of reference evapotranspiration using several artificial intelligence models: Application of different modeling scenarios. Theor. Appl. Clim. 2019, 135, 449-462. [CrossRef]

72. Saggi, M.K.; Jain, S. Reference evapotranspiration estimation and modeling of the Punjab northern India using deep learning. Comput. Electron. Agric. 2019, 156, 387-398. [CrossRef]

73. Chia, M.; Huang, Y.; Koo, C.; Fung, K. Recent advances in evapotranspiration estimation using artificial intelligence approaches with a focus on hybridization techniques-A review. Agronomy 2020, 10, 101. [CrossRef]

74. Li, X.; Liu, S.; Li, H.; Ma, Y.; Wang, J.; Zhang, Y.; Xu, Z.; Xu, T.; Song, L.; Yang, X.; et al. Intercomparison of six upscaling evapotranspiration methods: From site to the satellite pixel. J. Geophys. Res. Atmos. 2018, 123, 6777-6803. [CrossRef] 
75. Xu, T.; Guo, Z.; Liu, S.; He, X.; Meng, Y.; Xu, Z.; Xia, Y.; Xiao, J.; Zhang, Y.; Ma, Y.; et al. Evaluating Different Machine Learning Methods for Upscaling Evapotranspiration from Flux Towers to the Regional Scale. J. Geophys. Res. Atmos. 2018, 123, 8674-8690. [CrossRef]

76. Tang, D.; Feng, Y.; Gong, D.; Hao, W.; Cui, N. Evaluation of artificial intelligence models for actual crop evapotranspiration modeling in mulched and non-mulched maize croplands. Comp. Electron Agric. 2018, 152, 375-384. [CrossRef]

77. Duan, T.; Avati, A.; Ding, D.Y.; Basu, S.; Ng, A.Y.; Schuler, A. NGBoost: Natural Gradient Boosting for Probabilistic Prediction. arXiv 2019, arXiv:1910.03225.

78. Chen, T.; Guestrin, C. XGBoost: A scalable tree boosting system. In Proceedings of the 22nd ACM SIGKDD International Conference on Knowledge Discovery and Data Mining, San Francisco, CA, USA, 13-17 August 2016; pp. 785-794.

79. Lundberg, S.M.; Erion, G.; Chen, H.; DeGrave, A.; Prutkin, J.M.; Nair, B.; Katz, R.; Himmelfarb, J.; Bansal, N.; Lee, S.I. From local explanations to global understanding with explainable AI for trees. Nat. Mach. Intell. 2020, 2, 2522-5839. [CrossRef]

80. Devitt, T.J.; Wright, A.M.; Canntella, D.C.; Hillis, D.M. Species delimitation on endangered groundwater salamanders: Implications for aquifer management for biodiversity conservation. Proc. Natl. Acad. Sci. USA 2019, 116, 2624-2633. [CrossRef] [PubMed]

81. Dugas, W.A.; Hicks, R.A.; Wright, P. Effect of removal of Juniperus ashei on evapotranspiration and runoff in the Seco creek Yatershed. Water Resour. Res. 1998, 34, 1499-1506. [CrossRef]

82. Deng, K.; Ting, M.; Yang, S.; Tan, Y. Increased frequency of summer extreme heat waves over Texas area tied to the amplification of Pacific zonal SST gradient. J. Clim. 2018, 31, 5629-5647. [CrossRef]

83. Hoerling, M.; Kumar, A.; Dole, R.; Nielsen-Gammon, J.; Eischeid, J.; Perlwitz, J.; Quan, X.-W.; Perlwitz, J.; Quan, X.W.; Zhang, T.; et al. Anatomy of an extreme event. J. Clim. 2013, 26, 2811-2832. [CrossRef]

84. Rupp, D.E.; Li, S.; Massey, N.; Sparrow, S.N.; Mote, P.W.; Allen, M. Anthropogenic influence on the changing likelihood of an exceptionally warm summer in Texas, 2011. Geophys. Res. Lett. 2015, 42, 2392-2400. [CrossRef]

85. Mahler, B.; Bourgeais, R. Dissolved oxygen fluctuations in karst spring flow and implications for endemic species: Barton springs, Edwards aquifer, Texas, USA. J. Hydrol. 2013, 505, 291-298. [CrossRef]

86. Zhang, Y.Q.; Chiew, F.H.S.; Zhang, L.; Leuning, R.; Cleugh, H.A. Estimating catchment evaporation and runoff using MODIS leaf area index and the Penman-Monteith equation. Water Resour. Res. 2008, 44, W10420. [CrossRef]

87. Raza, D.S.M.H.; Mahmood, S.A. Estimation of net rice production through improved CASA model by addition of soil suitability constant $(h \alpha)$. Sustainability 2018, 10, 1788. [CrossRef]

88. Meyer, A.F. Computing Runoff from Rainfall and Other Physical Data. Trans. Am. Soc. Civ. Eng. 1915, 79, 1055-1155.

89. Guidotti, R.; Monreale, A.; Ruggieri, S.; Turini, F.; Pedreschi, D.; Giannotti, F. A Survey of Methods for Explaining Black Box Models. ACM Comput. Surv. 2018, 51, 93. [CrossRef]

90. Hargreaves, G.; Samani, Z. Reference crop evapotranspiration from temperature. Appl. Eng. Agric. 1985, 1, 96-99. [CrossRef]

91. Yoo, B.H.; Kim, J.; Byun-Woo, L.; Hoogenboom, G.; Kim, K.S. A surrogate weighted mean ensemble method to reduce the uncertainty at a regional scale for the calculation of potential evapotranspiration. Sci. Rep. 2020, 10, 870. [CrossRef] [PubMed]

92. Gong, L.; Xu, C.Y.; Chen, D.; Halldin, S.; Chen, Y.D. Sensitivity of the Penman-Monteith reference evapotranspiration to key climatic variables in the Changjiang (Yangtze River) basin. J. Hydrol. 2006, 329, 620-629. [CrossRef]

93. Yan, H.; Shugart, H.H. An air relative-humidity-based evapotranspiration model from Eddy covariance data. J. Geophys. Res. Atmos. 2010, 115. [CrossRef]

94. Wobus, C.; Zarakas, C.; Malek, P.; Sanderson, B.; Crimmins, A.; Kolian, M.; Sarofim, M.; Weaver, C. Reframing Future Risks of Extreme Heat in the United States. Earths Future 2018, 6, 1323-1335. [CrossRef] [PubMed]

95. Thompson, S.A. Water Use, Management, and Planning In the United States; Academic Press: San Diego, CA, USA, 1999. 